Article

\title{
Effects of Unequal Lot Size and Variable Transportation in Unreliable Supply Chain Management
}

\author{
Soumya Kanti Hota ${ }^{1,2} \mathbb{D}$, Biswajit Sarkar ${ }^{3, * \mathbb{D}}$ and Santanu Kumar Ghosh ${ }^{1}$ (D) \\ 1 Department of Mathematics, Kazi Nazrul University , Nazrul Road, Kalla Bypass More, P.O.-Kalla (C. H.) \\ Asansol, West Bengal 713340, India; soumyakanti.hota@knu.ac.in or soumya.hota277@gmail.com (S.K.H.); \\ santanukumar.ghosh@knu.ac.in (S.K.G.) \\ 2 Department of Mathematics, Debra Thana Sahid Kshudiram Smriti Mahavidyalaya, Debra, \\ Paschim Medinipur, West Bengal 721101, India \\ 3 Department of Industrial Engineering, Yonsei University, 50 Yonsei-ro, Sinchon-dong, Seodaemun-gu, \\ Seoul 03722, Korea \\ * Correspondence: bsbiswajitsarkar@gmail.com or bsarkar@yonsei.ac.kr; Tel.: +82-10-7498-1981
}

Received: 28 January 2020; Accepted: 24 February 2020; Published: 5 March 2020

\begin{abstract}
The effect of unreliable players on the supply chain management with a single-setup-multiunequal-increasing-delivery-policy (SSMUID) along with a service-dependent demand and investment is discussed in this model. The manufacturer is unreliable which causes an increase of lead time and shortage. For solving the shortage problem and reducing lead time crashing cost (LTCC), an investment is utilized with the variable backorder price discounts. The number of transportation increases due to the new transportation policy and it causes pollution. Besides the fixed transportation and carbon emission cost (FTCEC), a container dependent carbon emission cost is applied. Some investments for setup cost reduction (SCR), ordering cost reduction (OCR), and quality improvement (QI) are considered. The lead time demand follows a normal distribution. The total cost of the supply chain is optimized and the model is tested numerically. The main intent of this study is to solve the shortage problem which occurs due to unreliability of the manufacturer. The study helps to reduce the unreliability issue of the manufacturer. The objective function is solved by using the classical optimization technique. Numerical results show that the discount for partial backorder enhances the profitability of the manufacturer. The sensitiveness of the parameters are discussed through the sensitivity of analysis and some special cases. Managerial insights provide the applicability of this study among different sectors.
\end{abstract}

Keywords: supply chain management; service; quality; transportation; production; carbon footprint

\section{Introduction}

Unreliability of players within a supply chain is a big issue to run a supply chain smoothly. In the traditional supply chain, the players of the supply chain are honest, but now there are some players who are opportunistic and they hide information about products, prices, delivery times, qualities, and services. In the present marketing trends, the customer wants quick and on-time delivery, but due to unreliability issue of the manufacturer, the retailer faces a shortage problem. Hence customers may not get their products at the required time and they move to the different retailers to buy similar products. As a result, the retailer loses faith. For this reason, the company losses the reputation and as a result, the demand of the product decreases which creates trouble for the production house. Thus, it is a big headache for the industry to control the unreliable player problem and run the supply chain smoothly. In this proposed study, the shortage problem which arises due to the unreliability of the 
manufacturer is discussed. Simultaneously, a way of solution for the shortage problem due to consider the variable backorder price discount is discussed.

Nowadays, the coordination between the supply chain management (SCM) cannot be assured of the minimization of cost with the coordination policy only. Due to the concept of internet of things (IoT) and the smart production, it is found that several non-coordinated supply chain can give profitable than the coordination of the SCM. The introduction of block-chain influences a lot in this direction (Sarkar and Lee [1]). In this way, the impact of industrial revolution and European Union 2014 create a new dimension for the SCM to reduce the global warming along with the minimization of cost by maintaining the quality of products in all aspects. The major benefit by using cloud computing can be easily applied in the advanced SCM to reduce the global warming issues. The main reason behind global warming is the carbon emission from the production house and discharging carbon dioxide and carbon monoxide during transportation through different capacitated vehicles. Among these two carbon emissions, it is found from the literature that for most of the green products, the transportation gives more carbon emission than the production house (Ahmad and Sarkar [2]). Thus, for any green SCM, it is necessary to take care of the transportation issues. However, single-setup-single-delivery (SSSD) policy always diverges for more setup cost (SC) and more holding cost (HC) whereas single-setup-multi-delivery (SSMD) can solve the issues of reduction of SC and HC. Even though SSMD solves those issues but it cannot be assured of the necessity of exact amount of products for the retailer at that moment. It is quite natural that the demand is increasing for any product day by day but the SSMD policy gives an equal amount of product by every shipment. Therefore, the policy of this transportation mode has to be changed by the necessity of the demand for customers. Sarkar et al. [3] introduced a single-setup-multi-unequal-delivery (SSMUD) policy to solve the above mention issues, but they could not think about the reliability of players within an SCM. If the retailer or manufacturer, any of the player or both players are not reliable enough to continue the supply chain, though they are in contract, what will happen for the supply chain profit or total cost minimization? The existing research gap fulfilled by this proposed study to obtain the minimum cost (global), when global warming through the carbon emission control is utilized. However, if the supply chain is unreliable and they are taking care of global warming, then how much service they can provide to the customers, this is a big challenge. The proposed study optimizes the maximum performance of service to customers by its service dependent demand pattern; i.e., if the service is more, demand for those green products are obviously more and vice-versa. Therefore, this research completes the research gap for reducing global warming, optimizing unreliability of supply chain, maximizing the service for customers, and minimizing the global cost globally.

\section{Literature Review}

SCM is a collaboration between the manufacturers, suppliers, retailers, transporters, and the other players. It is an umbrella which covers the manufacture-retailer relationship. Goyel [4] first investigated about the vendor-buyer supply chain model. Since then, several authors like Banerjee [5], Hill [6], Goyal and Nebebe [7], Sarkar et al. [8] extended that study in several dimension which explain different situations by their mathematical modelling and found solutions. Recently, Tiwari et al. [9], Dey et al. [10], Tayyab et al. [11], Saxena et al. [12], Mishra et al. [13], Ullah et al. [14] extended SCM models by introducing various social and environmental concepts. However, they did not consider the case of unreliability in their studies.

The unreliability of players is a big challenge for running a supply chain smoothly. In the traditional supply chain models, players are honest and reliable. They do not hide sales information. Nowadays, players are unreliable and they hide information about many things like delivery time, quality, quantity from other players and as a result others players facing problems. In this study, the manufacturer is unreliable who hide information of delivered quantity from retailer. The manufacturer used to deliver a fraction of the order quantity ordered by the retailer and as a result, the retailer faced problem not only for the uncertainty of the ordered quantity also from 
inaccurate estimation. Instead of such problems, the retailer has no option to reject the manufacturer because there are very few manufacturers manufacturing such types of products and the quality of the raw materials used by the manufacturer are very good. Mukhopadhyay and Ma [15] discussed about the lot unreliable supplier in his model. Then, Fera et al. [16] discussed the effect of uncertainty for manufacturer in supply chains which described a method to analyze the competitiveness occurs from the situations of the order in distinct areas. Martino et al. [17] illustrated the risk assessment of supply chain in the fashion retailed industry which focused on a specified field of this industry and proved the efficiency of the supply chain in terms of correction management.

Inderfurth and Kiesmüller [18] first considered unreliable supplier in their model. Bernaus et al. [19] discussed uncertainty in e-commerce. They invented an approach, namely "simheuristic", for dealing with large-scale events in small-computing time. Sawik [20] developed a risk-averse approach in the two-stage stochastic integrated model. Xu et al. [21] represented a comprehensive overview and visualisation in the field of supply chain disruption based on several research papers. Kaczmarczyk [22] considered mixed-integer linear programming models of lot-sizing and scheduling problem. However, none of the authors considered shortage problem due to unreliability and solved it using variable backorder price discount in his research models. Thus, there is a research gap and this proposed model fulfils the gap. In this proposed study, the manufacturer is unreliable who delivers a fraction of the ordered quantity by the retailer through single-setup-multi-unequal-increasing-delivery-policy (SSMUID) policy (see Figure 1)which causes shortage and the problem of shortage is trying to solve by variable backorder price discount.

An important issue in any supply chain is service. Good service satisfies customers, but on the other hand bad service may decrease the reputation of the manufacturer. At the time of service, the manufacturer may delay allowing service. Even customers can not contact with them at the time of service. As a result, under compulsion customers go for paid servicing. An inventory model was investigated by Chen and Krass [23], to minimize the service level (SL) in a place of stockout cost. Hwang [24] designed a logistic system for supply chain under the consideration of SL. Chiu et al. [25] developed a remanufacturing model with optimized production lot size and rework. In that model, they used an SL constraint and optimized the scrap rate. The service-level was considered as a decision variable by Jodlbauer and Reitner [26]. The optimization of the total cost of a stochastic multi-item make-to-order (MTO) system of production was developed by Jodlbauer and Reitner [26]. In this direction, a distribution-free model with continuous reviewed was provided by Moon et al. [27]. In the model, they considered an SL and variable lead time as a constraint. Shin et al. [28] explained a stochastic modelling with SL as constraint along with a controllable lead time. Recently several researchers developed different types of optimization model. Albrecht [29], Gruson et al. [30], Jain and Bala [31] developed mathematical for a production system and proved that SL constraint has a great impact on any smart production system. In traditional supply chain models, demand is assumed to be constant but practically demand depends on many factors like price, availability, advertisement, the popularity of the product, discount, and most importantly, on the service of the product. If the service of a product is not good then the demand for the product must be reduced. An investment for improvement of the service is applied which was first introduced by Lin [32]. None of the authors considered service dependent demand in a model with unreliable manufacturer where shortage arises due to unreliability, variable backorder price discount, and SSMUID policy. This model fulfils this gap by considering unreliability in an SCM with service dependent demand, SSMUID policy, variable backorder price discount, and fixed and variable transportation and carbon emission cost (VTCEC). 


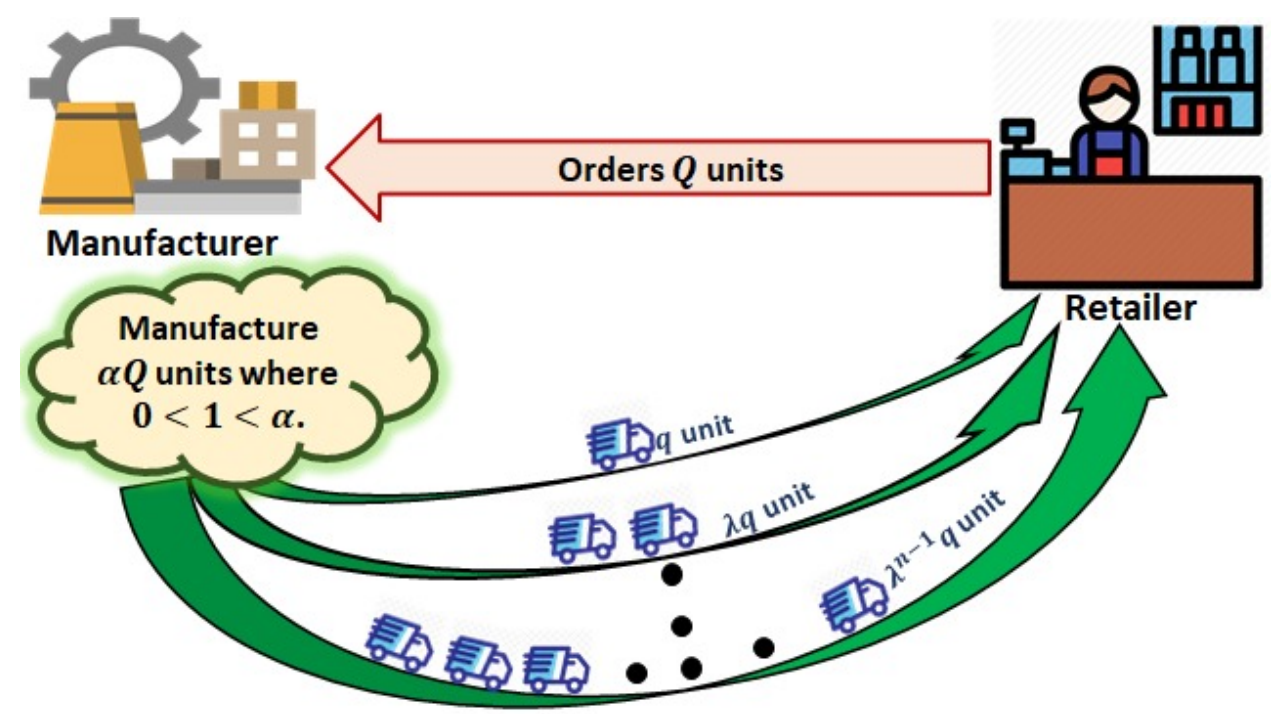

Figure 1. Single-setup-multi-unequal-increasing-delivery (SSMUID) policy.

Due to the long-run, the production system may go to out-of-order state and as a result imperfect (defective), as well as perfect quality items, are produced continuously. With some fixed cost, the imperfect items can be made as perfect. Recently, Sarkar et al. [33] invested some cost for improve the defective production problem. According to Moon et al. [27], to minimized the imperfect production, an continuous investment function as a logarithmic function is applied in this study which was firstly introduced by Porteus [34]. All investments are necessary for an unreliable manufacturer which is discussed in this proposed study.

Increasing number of transportation must effects on the transportation and carbon emission cost (TCEC). It was considered by Sarkar [35]. The VTCEC may depend on several matters like distance, time, lot size etc. In this study, besides a fixed transportation and carbon emission cost (FTCEC), a capacity dependent TCEC is applied. Sawik [36] minimized the pollution, carbon emission, noise, and fuel consumption and maximize the capacity of the truck in the study related to multi-criterion vehicle routing problem. However, none of them considered yet unreliability of the manufacturer in their models.

In this proposed model, the manufacturer is unreliable who delivers a fraction of order quantity to the retailer. For this reason shortages arise and there are lost sales. The manufacturer delivers the quantity in multi-shipments and creates an increasing demand situation of the product. The quantity of the lot sizes per shipments increases in such a way that every lot size is a fixed multiple of the previous lot size. Investments for reducing the SC, OC, QI, and SL improvement are applied in the study. An increasing number of transportation effects on pollution and hence beside of a FTCEC, a VTCEC are considered in this model. To reduce the lead time, a LTCC is applied in this study. HC for both the manufacturer and the retailer are considered in this study and finally, the shortage problem is trying to solve by considering the variable backorder price discount. In this way, this model fulfils the research gap between the unreliability, SSMUID policy, variable backorder, SL, and VTCEC. The SC and ordering cost is reduced by some discrete investments and the quality and service of the product are improved by some investment. Table 1 gives the contributions of various authors in this field.

The structure of the manuscript is as follows. Section 3 gives assumptions, notations, as well as the problem discussion of this study. The mathematical derivation is discussed in Section 4. A normal distribution case is discussed in Section 5. A numerical example with sensitivity analysis and special cases are discussed in Section 6. Section 7 gives conclusions and its future extension. 
Table 1. Author(s) contribution table.

\begin{tabular}{|c|c|c|c|c|c|c|}
\hline Author(s) & $\begin{array}{l}\text { Manu-Facturer } \\
\text { Type }\end{array}$ & Demand Type & $\begin{array}{c}\text { Transportation and Carbon } \\
\text { Emission Cost }\end{array}$ & $\begin{array}{l}\text { Shipment } \\
\text { Strategy }\end{array}$ & $\begin{array}{c}\text { Backorder Price } \\
\text { Discount }\end{array}$ & Investment \\
\hline Glock [37] & Rel. & Cons. & NA & SSSD & NA & NA \\
\hline Moon et al. [27] & Rel. & Cons. & NA & SSSD & NA & SCR, QI \\
\hline Sarkar et al. [38] & Rel. & Cons. & NA & SSSD & Variable & QI \\
\hline Ouyang et al. [39] & Rel. & Cons. & NA & SSSD & NA & SCR, QI \\
\hline Lee $[40]$ & Unreliable & Cons. & NA & NA & NA & NA \\
\hline Wu et al. [41] & Rel. & Cons. & NA & NA & NA & NA \\
\hline Sarkar and Majumdar [42] & Rel. & Cons. & NA & SSMD & NA & SCR \\
\hline Sarkar et al. [43] & Rel. & Cons. & Demand and quantity dependent & SSMD & NA & NA \\
\hline Mukhopadhyay and Ma [15] & Rel. & Cons. & NA & NA & NA & NA \\
\hline Majumdar et al. [44] & Rel. & NA & NA & SSMD & NA & Lead time \\
\hline Dey et al. [45] & NA & Price & Quantity dependent & SSMD & NA & SCR \\
\hline Guchhait et al. [46] & Rel. & Cons. & NA & SSSD & NA & NA \\
\hline Dey et al. [47] & NA & Cons. & Quantity & SSMD & NA & $\mathrm{SC}, \mathrm{ST}$ \\
\hline This model & Unreliable & Service dependent & Container dependent & SSMUID & Variable & $\begin{array}{c}\text { SCR, OCR } \\
\text { QI, } \\
\text { Service } \\
\text { improvement }\end{array}$ \\
\hline
\end{tabular}




\section{Problem Discussion, Notation, and Assumptions}

\subsection{Problem Discussion}

A continuous inventory model is considered. The retailer placed an order to the manufacturer just after reaching the inventory to the reorder point. Since SCR for the manufacturer is necessary for a supply chain, thus, an investment for reducing SC is applied. The manufacturer in this study are unreliable who send a faction of the quantity ordered by the retailer in several lots to reduce the $\mathrm{HC}$ of the retailer. Keeping the increasing demand of the product in mind the lot sizes are taken unequal and they increased in a multiple of geometric progression series of the first lot. When a system runs long then the system may be going to an out-of-control stage and defective items may produce from the system. Thus, besides a defective cost for manufacture, to upgrade the quality of the product several investments for quality are considered. Since every people wants quick and on-time delivery thus, short lead time can make a product attractive. However, due to the unreliability of the manufacturer the lead time may be long and as an effect shortages may be arises. Thus, the LTCC is applied. Again because of unreliability of manufacture, less quantity and long delivery time make some customers disappointed. As a result, a number of customers go to other retailer to buy the product and some of them wait for the product especially if the delivery time is small and for the good reputation of the retailer. For that an annual stock out is considered in this model.

\subsection{Assumptions}

1. The inventory model is found as continuous. The demand depends on the service of the manufacturer. The demand pattern follows as $D=\kappa_{1} \rho^{\kappa_{2}}$.

2. Discrete investments be utilized for the manufacturer and the retailer of the supply chain model, for reference, see Sarkar et al. [3].

3. According to Ouyang et al. [39], $I_{\theta}(\theta)=b \log \left(\frac{\theta_{0}}{\theta}\right)$ for $0<\theta \leq \theta_{0}$ is the continuous capital investment function, which is invested to improve the quality of the product during the system may goes to out-of-control stage and imperfect items may produce.

4. Due to unreliability of the manufacturer, the lead time may be long and as a result, the reputation of the company and the retailer goes down. The LTCC, which are applied for reducing the lead time and as a result improving the satisfaction of the customer is considered in this model. Taking the minimal duration $u_{i}$ with a crashing cost $m_{i}$ per unit of time and a normal duration $v_{i}$, the lead time $L$ is divided into $n$ components $L_{1}, L_{2}, \ldots, L_{n}$, which are mutually independent and each of the component $L_{i}$ may be reduced from $v_{i}$ to any volume between $v_{i}$ and $u_{i}$ i.e., $L_{i} \in\left[u_{i}, v_{i}\right]$ for all $i$. Rearrangement of the components are done in such a way that $m_{1} \leq m_{2} \leq m_{3} \leq \cdots \leq$ $m_{n}$ that is the least crashing cost occurred in the first component and the highest crashing cost occurred in the last component etc. The time beginning with the lowest crashing cost $m_{i}$, the component $L_{i}$ is crashed (Liao and Shyu [48]). Let $l_{i}=u_{i}$, i.e., the components are crashed to their minimum duration. Then, for all $i=1,2, \ldots, n, L_{\text {min }} \leq \sum_{i=1}^{n} u_{i} \leq L \leq \sum_{i=1}^{n} v_{i} \leq L_{\text {max }}$. It follows that the lead time length crashed at their minimum duration $L_{i}=\sum_{j=1}^{n} v_{j}-\sum_{j=1}^{i}\left(v_{j}-\right.$ $\left.u_{j}\right)=\sum_{j=i+1}^{n} v_{j}+\sum_{j=1}^{i} u_{j}$ for $i=1,2, \ldots, n$ and the LTCC for a given $L_{j} \leq L<\leq L_{j}-1$ is given by $C(L)=m_{i}\left(L_{i-1}-L\right)+\sum_{j=1}^{i-1} m_{j}\left(v_{j}-u_{j}\right)$ for $i=1,2, \ldots, n$.

5. An amount $Q$ of order is placed to the manufacturer by the retailer just after reaching the inventory to the reorder point $r$.

6. After getting order the manufacturer manufacture a fraction $\alpha Q$ of the ordered quantity $Q$ is delivered to the retailer where $0<\alpha<1$.

7. For reducing $\mathrm{HC}$, the $\alpha Q$ quantity can be shipped by $n$ shipments. The lot size in each shipment are unequal.

8. The manufacturer transports first lot of size $q$ units, second lot of size $\varsigma q$, third lot of size $\varsigma^{2} q, \ldots$, $n$th lot of size $\varsigma^{n-1} q$ where $\varsigma>1$ is a constant. 
9. Due to unreliability of the manufacturer shortages arise and shortages are partially backlogged.

10. The expression of the backorder ratio $\varrho$ is $\frac{\varrho_{0} \pi_{x}}{\pi_{0}}$, where the price discount in the time period of maximum backorder $0 \leq \varrho_{0}<1$ is $0 \leq \pi_{x} \leq \pi_{0}, \pi_{0}$ is the marginal profit per unit (Pan et al. [49], Lin [32]).

\section{Formulation of the Model}

In this retailer-manufacturer continuous inventory model, where the manufacturer is unreliable, after reaching the inventory to the reorder point $r$ (decision variable) the retailer placed an order of $Q$ quantity to the manufacturer. Discrete investments $A_{0} e^{-\kappa A}$, and $V_{0} e^{-\mu I}$ are applied for reducing the ordering cost and the SC. However, due to unreliability issue, the manufacturer produces and sends a fraction $\alpha Q, 0<\alpha<1$ of the order quantity $Q$ to the retailer without informing him with the fixed and variable TCEC $C_{F T}^{S}, C_{V T}^{S}, C_{F C}^{S}$ and $C_{V C}^{S}$, respectively. In that situation, the retailer has no option in hand and he is bound for accepting the delivered products. Again the unreliable manufacturer transports the produced amount in $(n>1$, integer variable) lots to the retailer for reducing the HC of the retailer. Keeping the demand of the product in mind, the lot sizes, sent by the manufacturer, are increased in a multiple of the previous lot. The first lot is sent by the manufacturer as $q$, the second lot is sent by the manufacturer as $\varsigma q$ and in the same way, the last lot is sent by the manufacturer is $\varsigma^{n-1} q$. Therefore, the production batch, which transported from manufacturer to retailer, is

$$
q+\varsigma q+\varsigma^{2} q+\cdots+\varsigma^{n-1} q=q\left(\frac{\varsigma^{n}-1}{s-1}\right) .
$$

Since the total delivered quantity is $\alpha Q$ (Assumption 6), therefore, one can write

$$
q\left(\frac{\varsigma^{n}-1}{\varsigma-1}\right)=\alpha Q
$$

Thus, the number of production cycle is $\frac{D}{\alpha Q}$ that is $\frac{D(\varsigma-1)}{q\left(\varsigma^{n}-1\right)}$. For the unreliability of the manufacturer shortage must arise and thus, there must be some backorder with the rate $\varrho . E(X-r)^{+}$is the expected shortage, where $X$ is the demand during the lead time. Thus, the number of backorder and lost sales per cycle are $\varrho E(X-r)^{+}$and $(1-\varrho) E(X-r)^{+}$. Due to long-run, the system may go to out-of-order stage and as a result, along with the good items, some defective items are also produced continuously. For fixing the defective items by improving its quality, a continuous investment $I_{\theta}(\theta)$ for quality improvement is applied and an investment $\eta \rho^{2}$ is applied to improve the service. Figures 2 and 3 respectively represent manufacturer and retailer's inventory.

\subsection{Manufacturer's Mathematical Model}

To calculate the manufacturer's total cost, the following cost are calculated as follows:

\subsubsection{Total SC of Manufacturer with Investment}

The total SC of manufacturer is

$$
\left[V_{0} e^{-\mu I}+I\right] \frac{D}{\alpha Q^{\prime}}
$$

where $\mu$ is a known parameter and $I$ is a decision variable. 


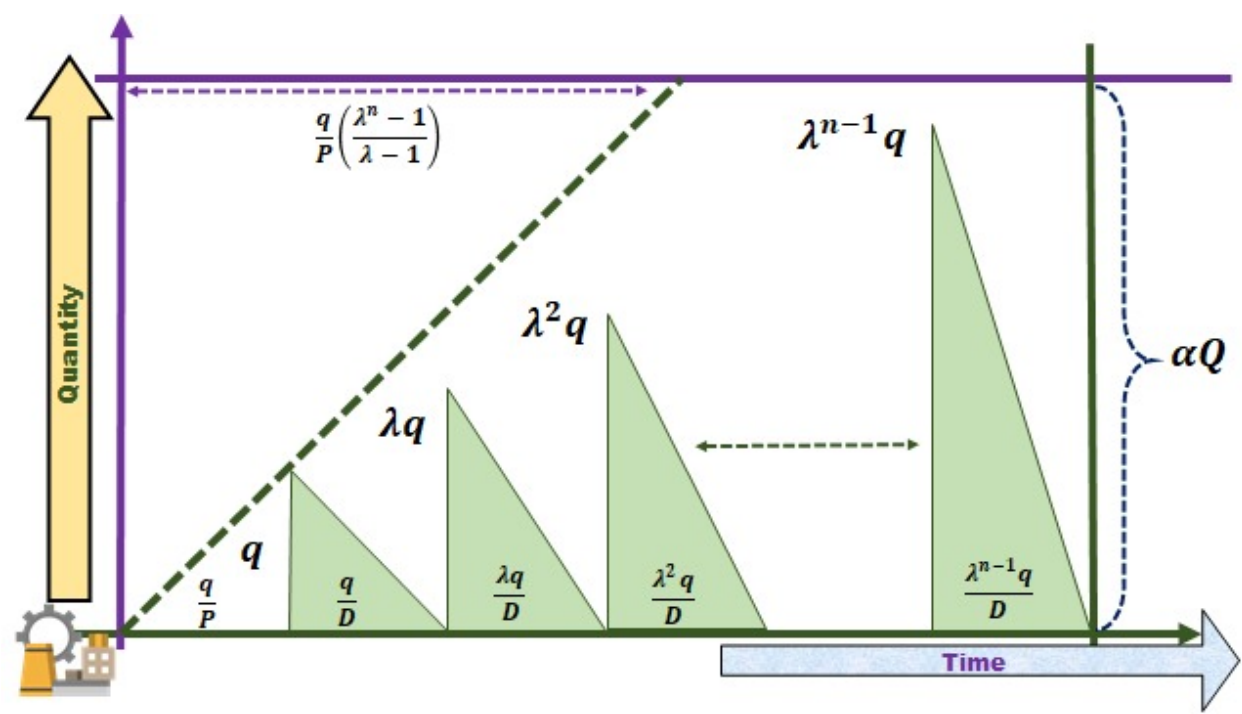

Figure 2. Figure of the manufacturer.

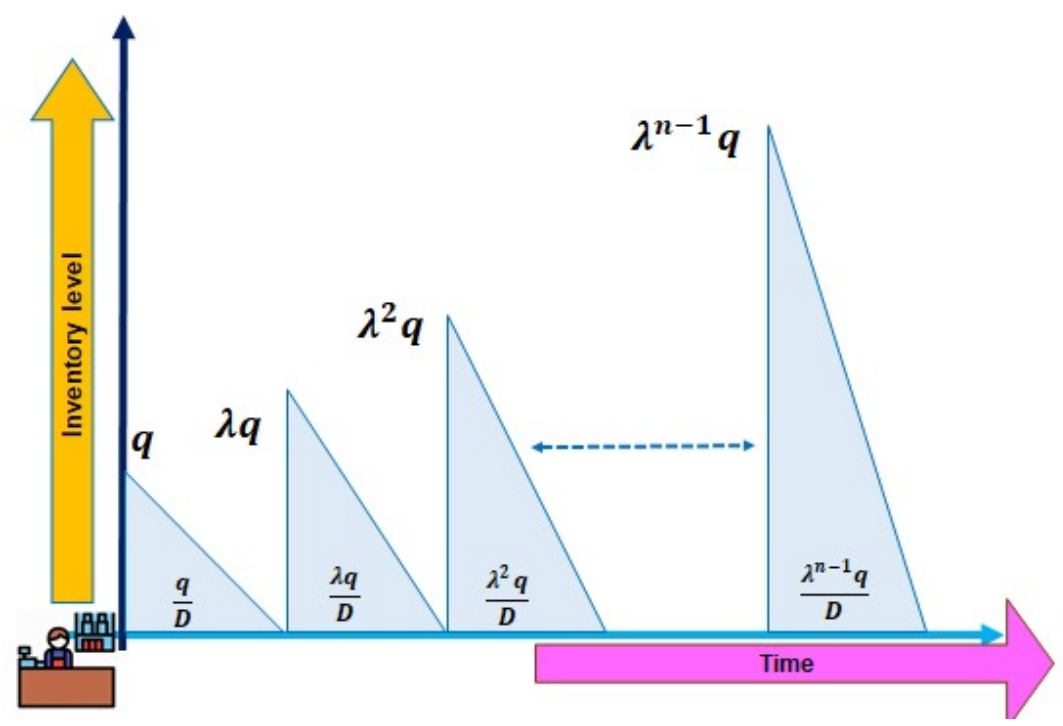

Figure 3. Inventory position of the retailer.

\subsubsection{HC of the Manufacturer}

After calculating the total inventory of the manufacturer from Figure 2, the total HC of the manufacturer is obtained as follows (Sarkar et al. [3]).

$$
q\left[\frac{D}{P}+\left(1-\frac{D}{2 P}\right)\left(\frac{\varsigma^{n}-1}{\varsigma-1}\right)-\frac{1}{2}\left(\frac{\varsigma^{n}+1}{\varsigma+1}\right)\right] C_{H}^{M} .
$$

\subsubsection{Defective Cost of the Manufacturer}

During flow time for long-run, the system may go to an out-of-control stage with probability $\theta$, which is in general very small and close to zero. Porteus [34] introduced the expression of the defective cost. Then, Moon et al. [27] applied this expression in his model. Recently Sarkar et al. [33] applied this. Thus, the expected annual defective cost is as follows (see Porteus [34]).

$$
\frac{s D \theta \alpha Q}{2}
$$




\subsubsection{Capital Investment Cost of the Manufacture}

As the system continuously produces defective items during for its out-of-control stage, to fix those defective items, an investment is applied. Ouyang et al. [39] first introduced this cost. Then, Moon et al. [27] and Sarkar et al. [33] applied this expression in their models. According to the investment for make the defective items perfect is $b I_{\theta}(\theta)$. Therefore, the expected annual investment cost is

$$
a I_{\theta}(\theta)=a b \log \left(\frac{\theta_{0}}{\theta}\right)
$$

\subsubsection{TCEC of the Manufacturer}

For the SSMUID policy, the number of transportation increases. Thus, beside of FTCEC of the manufacturer, a variable transportation and a carbon emission cost are need to be considered. Sarkar et al. [50] first introduced container capacity-dependent variable transportation and carbon emission cost (VTCEC).

Thus, the manufacturer's total FTCEC is

$$
=n \frac{D}{\alpha Q}\left[C_{F T}^{S}+C_{F C}^{S}\right] .
$$

Considering the capacity of each container $\gamma$ as fixed, the manufacturer's total VTCEC is

$$
=\frac{\alpha Q}{\gamma}\left[C_{V T}^{S}+C_{V C}^{S}\right]
$$

Therefore, total TCEC of the manufacturer is

$$
=n \frac{D}{\alpha Q}\left[C_{F T}^{S}+C_{F C}^{S}\right]+\frac{\alpha Q}{\gamma}\left[C_{V T}^{S}+C_{V C}^{S}\right] .
$$

4.1.6. Investment Cost for Improvement of Quality

In this model, an investment $\eta \rho^{2}$ is considered, where $\eta$ is the constant of coefficient is introduced for improvement of the service of the manufacturer to attract customers and increase the reputation of the company.

\subsubsection{Total Cost of the Manufacturer}

From the above-mentioned cost, the total cost of the manufacturer is as follows

$$
\begin{aligned}
& \operatorname{ATC}_{M}(q, \varsigma, \rho, I, \theta, n)= \\
& {\left[V_{0} e^{-\mu I}+I\right] \frac{D}{\alpha Q}+q\left[\frac{D}{P}+\left(1-\frac{D}{2 P}\right)\left(\frac{\varsigma^{n}-1}{\varsigma-1}\right)-\frac{1}{2}\left(\frac{\varsigma^{n}+1}{\varsigma+1}\right)\right] C_{H}^{M}} \\
& +\frac{s D \theta \alpha Q}{2}+a b \log \left(\frac{\theta_{0}}{\theta}\right)+n \frac{D}{\alpha Q}\left[C_{F T}^{S}+C_{F C}^{S}\right]+\frac{\alpha Q}{\gamma}\left[C_{V T}^{S}+C_{V C}^{S}\right] \\
& +\eta \rho^{2}
\end{aligned}
$$

where $0<\theta \leq \theta_{0}$.

\subsection{Retailer's Mathematical Model}

To calculated the total cost of the retailer, the following costs are needed to calculate. 


\subsubsection{Discrete Investment for OCR}

To reduce the ordering cost for the retailer, some extra investments are introduced. Thus, the total ordering cost of the retailer is

$$
\frac{D}{\alpha Q}\left[A_{0} e^{-\kappa A}+A\right]
$$

\subsubsection{LTCC of the Retailer}

The LTCC is given by $C(L)=m_{i}\left(L_{i}-1-L\right)+\sum_{j=1}^{i-1} m_{j}\left(v_{j}-u_{j}\right)$. Therefore, the expected annual crashing cost per cycle is

$$
\frac{D}{\alpha Q}\left[m_{i}\left(L_{i-1}-L\right)+\sum_{j=1}^{i-1} m_{j}\left(v_{j}-u_{j}\right)\right] .
$$

\subsubsection{Annual Stockout Cost of the Retailer}

An amount $Q$ of the order quantity is placed to manufacturer by the retailer just after reaching the inventory to the reorder point $r$. However, due to unreliable manufacturer the retailer receives only a fraction $\alpha Q$ of the order quantity. The demand during lead time is a random variable $(X)$ with mean $D L$ and standard deviation $\sigma \sqrt{L}$. Then, $\varrho E(X-r)^{+}$is the expected backorders number per cycle and hence the annual (expected) stockout cost is as follows (see Sarkar et al. [38]).

$$
\frac{D}{\alpha Q}\left[\pi_{x} \varrho+\pi_{0}(1-\varrho)\right] E(X-r)^{+} .
$$

\subsubsection{HC of the Retailer}

From Figure 3, one can obtained the total number of holding items $=\frac{q\left(\varsigma^{n}+1\right)}{2(\varsigma+1)}$.

The expected backorder number is $\varrho E(X-r)^{+}$and per cycle lost sales is $(1-\varrho) E(X-r)^{+}$. Thus, the total HC for retailer is

$$
\left[\frac{q\left(\varsigma^{n}+1\right)}{2(\varsigma+1)}+r-D L+(1-\varrho) E(X-r)^{+}\right] C_{H}^{R} .
$$

4.2.5. Total Cost of the Retailer

From the above costs, the total cost of the retailer is

$$
\begin{aligned}
& \operatorname{ATC}_{R}\left(q, \varsigma, \rho, A, L, \pi_{x}, k\right)= \\
& \frac{D}{\alpha Q}\left[A_{0} e^{-\kappa A}+A\right]+\frac{D}{\alpha Q}\left[m_{i}\left(L_{i-1}-L\right)+\sum_{j=1}^{i-1} m_{j}\left(v_{j}-u_{j}\right)\right] \\
& +\frac{D}{\alpha Q}\left[\pi_{x} \varrho+\pi_{0}(1-\varrho)\right] E(X-r)^{+} \\
& +\left[\frac{q\left(\varsigma^{n}+1\right)}{2(\varsigma+1)}+r-D L+(1-\varrho) E(X-r)^{+}\right] C_{H}^{R},
\end{aligned}
$$

where $0 \leq \varrho_{0}<1,0 \leq \pi_{x} \leq \pi_{0}$. 


\subsection{Total Cost of the SCM}

From (8) and (13), the joint expected total cost (per cycle) of the retailer and the manufacturer is as follows:

$$
\begin{aligned}
& \operatorname{JATC}\left(q, \varsigma, \rho, I, \theta, n, A, L, \pi_{x}, k\right) \\
& =\operatorname{ATC}_{M}(q, \varsigma, \rho, I, \theta, n)+\operatorname{ATC}_{R}\left(q, \varsigma, \rho, A, L, \pi_{x}, k\right) \\
& =\left[V_{0} e^{-\mu I}+I\right] \frac{D}{\alpha Q}+q\left[\frac{D}{P}+\left(1-\frac{D}{2 P}\right)\left(\frac{\varsigma^{n}-1}{\varsigma-1}\right)-\frac{1}{2}\left(\frac{\varsigma^{n}+1}{\varsigma+1}\right)\right] C_{H}^{M} \\
& +\frac{s D \theta \alpha Q}{2}+a b \log \left(\frac{\theta_{0}}{\theta}\right)+n \frac{D}{\alpha Q}\left[C_{F T}^{S}+C_{F C}^{S}\right]+\frac{\alpha Q}{\gamma}\left[C_{V T}^{S}+C_{V C}^{S}\right] \\
& +\eta \rho^{2}+\frac{D}{\alpha Q}\left[A_{0} e^{-\kappa A}+A\right]+\frac{D}{\alpha Q}\left[m_{i}\left(L_{i-1}-L\right)+\sum_{j=1}^{i-1} m_{j}\left(v_{j}-u_{j}\right)\right] \\
& +\frac{D}{\alpha Q}\left[\pi_{x} \varrho+\pi_{0}(1-\varrho)\right] E(X-r)^{+} \\
& +\left[\frac{q\left(\varsigma^{n}+1\right)}{2(\varsigma+1)}+r-D L+(1-\varrho) E(X-r)^{+}\right] C_{H}^{R},
\end{aligned}
$$

where $0<\theta \leq \theta_{0}, 0 \leq \varrho_{0}<1,0 \leq \pi_{x} \leq \pi_{0}$. Thus, the problem is

$$
\underset{\theta \in\left(0, \theta_{0}\right], \pi_{x} \in\left[0, \pi_{0}\right]}{\operatorname{minimize}} \operatorname{JATC}\left(q, \varsigma, \rho, I, \theta, n, A, L, \pi_{x}, k\right)
$$

\section{Normal Distribution Model}

If the variable of the lead time demand $X$ follows a normal distribution with mean $D L$ and standard deviation $\sigma \sqrt{L}$, respectively, the reorder point $r$ is given by $r=\kappa_{1} \rho^{\kappa_{2}} L+k \sigma \sqrt{L}$ and hence, $E(X-r)^{+}=\sigma \sqrt{L} \psi(k)$. The value of $\psi(K)$ is $\psi(k)=\phi(k)-k[1-\Phi(k)]$, where the density function of the standard normal distribution is $\phi(k)$ and the distribution function of the standard normal distribution is $\Phi(k)$ (See Moon and Choi [51]). Now putting the values, the problem becomes

$$
\begin{aligned}
\underset{\theta \in\left(0, \theta_{0}\right], \pi_{x} \in\left[0, \pi_{0}\right]}{\operatorname{minimize}} J A T C & \left(q, \varsigma, \rho, I, \theta, n, A, L, \pi_{x}, k\right) \\
& =\frac{\kappa_{1} \rho^{\kappa_{2}}(\varsigma-1)}{q\left(\varsigma^{n}-1\right)}\left[V_{0} e^{-\mu I}+I\right] \\
& +q\left[\frac{\kappa_{1} \rho^{\kappa_{2}}}{P}+\left(1-\frac{\kappa_{1} \rho^{\kappa_{2}}}{2 P}\right)\left(\frac{\varsigma^{n}-1}{\varsigma-1}\right)-\frac{1}{2}\left(\frac{\varsigma^{n}+1}{\varsigma+1}\right)\right] C_{H}^{M} \\
& +\frac{s \kappa_{1} \rho^{\kappa_{2}} \theta q\left(\varsigma^{n}-1\right)}{2(\varsigma-1)}+a b \log \left(\frac{\theta_{0}}{\theta}\right)+n \frac{\kappa_{1} \rho^{\kappa_{2}}(\varsigma-1)}{q\left(\varsigma^{n}-1\right)} C_{F T}^{S} \\
& +\frac{q}{\gamma}\left(\frac{\varsigma^{n}-1}{\varsigma-1}\right) C_{V T}^{S}+n \frac{\kappa_{1} \rho^{\kappa_{2}}(\varsigma-1)}{q\left(\varsigma^{n}-1\right)} C_{F C}^{S}+\frac{q}{\gamma}\left(\frac{\varsigma^{n}-1}{\zeta-1}\right) C_{V C}^{S} \\
& +\frac{\kappa_{1} \rho^{\kappa_{2}}(\varsigma-1)}{q\left(\varsigma^{n}-1\right)}+\eta \rho^{2}+\frac{\kappa_{1} \rho^{\kappa_{2}}(\varsigma-1)}{q\left(\varsigma^{n}-1\right)}\left[A_{0} e^{-\kappa A}+A\right] \\
& +\frac{\kappa_{1} \rho^{\kappa_{2}}(\varsigma-1)}{q\left(\varsigma^{n}-1\right)}\left[m_{i}\left(L_{i-1}-L\right)+\sum_{j=1}^{i-1} m_{j}\left(v_{j}-u_{j}\right)\right] \\
& +\frac{\kappa_{1} \rho^{\kappa_{2}}(\varsigma-1)}{q\left(\varsigma^{n}-1\right)}\left[\pi_{0}-\varrho_{0} \pi_{x}+\frac{\varrho_{0}\left(\pi_{x}\right)^{2}}{\pi_{0}}\right] \sigma \sqrt{L} \psi(k) \\
& +\left[\frac{q\left(\varsigma^{n}+1\right)}{2(\zeta+1)}+k \sigma \sqrt{L}+\left(1-\frac{\varrho_{0} \pi_{x}}{\pi_{0}}\right) \sigma \sqrt{L} \psi(k)\right] C_{H}^{R} .
\end{aligned}
$$


Solution Methodology

The joint expected total cost can be expressed as

$$
\begin{aligned}
\text { JATC } & \left(q, \varsigma, \rho, I, \theta, n, A, L, \pi_{x}, k\right) \\
& =\frac{D}{q} f(\varsigma) R_{1}+q\left[\frac{R_{2}}{f(\varsigma)}+g(\varsigma) R_{3}+\frac{D}{P}\right]+a b \log \left(\frac{\theta_{0}}{\theta}\right) \\
& +\left[k+\left(1-\frac{\varrho_{0} \pi_{x}}{\pi_{0}}\right) \psi(k)\right] \sigma \sqrt{L} C_{H}^{R}+\eta \rho^{2},
\end{aligned}
$$

where the values of $f(\varsigma), g(\varsigma), R_{1}, R_{2}, R_{3}$ are given in Appendix A.

Ignoring the constraints $0<\theta \leq \theta_{0}$ to solve the non-linear program and denote $\operatorname{JATC}\left(I, \theta, \rho, \zeta, n, q, A, L, \pi_{x}, k\right)$ by simply $J$, differentiating partially $J$ twice with respect to $L$ one has

$$
\frac{\partial^{2} J}{\partial L^{2}}=-\frac{\sigma}{4 L^{\frac{3}{2}}}\left[\frac{D}{q} f(\varsigma) \bar{\pi} \psi(k)+\left\{k+\left(1-\frac{\varrho_{0} \pi_{x}}{\pi_{0}}\right) \psi(k)\right\} C_{H}^{R}\right] .
$$

Since, $0 \leq \varrho_{0}<1,0 \leq \pi_{x} \leq \pi_{0}$ it is clear from Equation (17) that,

$$
\frac{\partial^{2} J}{\partial L^{2}}<0
$$

Thus, for fixed $I, \theta, \varsigma, n, q, A, \pi_{x}, k, \rho$ the function $J$ is a concave function in $L$. Hence, the expected minimum cost (annual) will occur at $L_{i-1}$ which is the end point of $\left[L_{i}, L_{i-1}\right]$. Again, for $L \in\left[L_{i}, L_{i-1}\right]$, differentiating $J$ with respect to $I, \theta, \varsigma, q, A, \pi_{x}, k, \rho$, it is found as

$$
\begin{aligned}
& \frac{\partial J}{\partial I}=\frac{D}{q} f(\varsigma)\left(1-V_{0} \mu e^{-\mu I}\right) \\
& \frac{\partial J}{\partial \theta}=\frac{q}{f(\varsigma)} \frac{s D}{2}-\frac{a b}{\theta} \\
& \frac{\partial J}{\partial \zeta}=f^{\prime}(\varsigma)\left[\frac{D R_{1}}{q}-\frac{q R_{2}}{f(\varsigma)^{2}}\right]+g \prime(\varsigma) R_{3} \\
& \frac{\partial J}{\partial q}=-\frac{D}{q^{2}} f(\varsigma) R_{1}+\frac{R_{2}}{f(\varsigma)}+g(\varsigma) R_{3}+\frac{D}{P} \\
& \frac{\partial J}{\partial A}=\frac{D}{q} f(\varsigma)\left(1-A_{0} \kappa e^{-\kappa A}\right) \\
& \frac{\partial J}{\partial \pi_{x}}=\left[\frac{D}{q} f(\varsigma)\left(\frac{2 \beta_{0} \pi_{x}}{\pi_{0}}-\varrho_{0}\right)-\frac{C_{H}^{R}}{\pi_{0}}\right] \varrho_{0} \sigma \sqrt{L} \psi(K) \\
& \frac{\partial J}{\partial \rho}=\frac{1}{2} \frac{q}{f(\varsigma)}\left(s \theta-\frac{1}{P}\right) \kappa_{1} \kappa_{2} \rho^{\kappa_{2}-1}+2 \eta \rho .
\end{aligned}
$$


Now equating the Equations (18)-(24) with zero, the stationary points $I^{*}, \theta^{*}, \varsigma^{*}, q^{*}, A^{*}, \pi_{x}^{*}, \rho^{*}$ are as follows:

$$
\begin{aligned}
& I^{*}=\frac{1}{\mu} \log \left(\mu V_{0}\right) \\
& \theta^{*}=\frac{2 a b}{q s D} f(\varsigma) \\
& \varsigma^{*}=1+\left(\varsigma^{n}-1\right) \sqrt{\frac{q R_{2}}{\frac{D R_{1}}{q}+\frac{g^{\prime}(\varsigma)}{f^{\prime}(\zeta)} R_{3}}} \\
& q^{*}=\sqrt{\frac{D f(\varsigma) R_{1}}{\frac{R_{2}}{f(\varsigma)}+g(\varsigma) R_{3}+\frac{D}{P}}} \\
& A^{*}=\frac{1}{\kappa} \log \left(\kappa A_{0}\right) \\
& \pi_{x}^{*}=\frac{1}{2}\left(\pi_{0}+\frac{q C_{H}^{R}}{D f(\varsigma)}\right) \\
& \rho^{*}=\left[-\frac{2 \eta f(\varsigma)}{\kappa_{1} \kappa_{2}\left\{\frac{f\left(\varsigma^{*}\right)}{q^{*}} R_{1}^{*}+\frac{1}{2} \frac{q^{*}}{f\left(\varsigma^{*}\right)}\left(s \theta^{*}-\frac{1}{P}\right)+\frac{q^{*}}{P}\right\}}\right]^{\frac{1}{\kappa_{2}-1}} .
\end{aligned} .
$$

Proposition 1. For some fixed $L \in\left[L_{i}, L_{i-1}\right]$ the Hessian matrix for $\operatorname{JATC}\left(I, \theta, \varsigma, q, A, \pi_{x}, k, \rho\right)$ is positive definite at the point $\left(I^{*}, \theta^{*}, q^{*}, A^{*}, L^{*}, \pi_{x}^{*}, k^{*}\right)$

Proof. For proof follow Appendix B.

\section{Numerical Examples}

The numerical example is illustrated to validate for this model. Table 2 gives the lead time data while values of the parameters are given in Table 3.

Therefore, the globally minimized cost of the model is $\$ 1285.52$, with respect to the decision variable production investment per batch for reducing SC $I^{*}=\$ 540.62 /$ unit, out-of-control movement probability $\theta^{*}=0.000017$, increasing rate of the shipment lot size $\varsigma^{*}=1.46$, number of shipments $n^{*}=4$, initial lot size $q^{*}=14.69$ unit, retailer's investment for reducing ordering cost per ordered batch $A^{*}=\$ 10.10 /$ unit, replenishment lead time $L^{*}=3$ weeks, price discount for backorder per unit offered by the retailer $\pi_{x}=\$ 75.56 /$ unit, and safety factor $k^{*}=2.3$.

Table 2. Lead time data.

\begin{tabular}{cccc}
\hline $\begin{array}{c}\text { Lead Time Component } \\
\boldsymbol{i}\end{array}$ & $\begin{array}{c}\text { Normal Duration } \\
\boldsymbol{v}_{\boldsymbol{i}} \text { Days }\end{array}$ & $\begin{array}{c}\text { Minimum Duration } \\
\boldsymbol{u}_{\boldsymbol{i}} \text { Days }\end{array}$ & $\begin{array}{c}\text { Unit Crashing Cost } \\
\boldsymbol{m}_{\boldsymbol{i}} \text { (\$/Day) }\end{array}$ \\
\hline 1 & 20 & 6 & 0.4 \\
2 & 20 & 6 & 1.2 \\
3 & 16 & 9 & 5.0 \\
\hline
\end{tabular}


Table 3. Values of the parameters.

\begin{tabular}{clcl}
\hline Parameter & Values & Parameter & Values \\
\hline$A_{0}$ & $\$ 50 /$ order & $\kappa$ & 0.25 \\
$\kappa_{1}$ & 30 & $\kappa_{2}$ & 1.5 \\
$D$ & 26.67 unit & $Q$ & 150 unit \\
$\alpha$ & $75.85 \%$ & $\alpha Q$ & 113.78 unit \\
$P$ & 60 unit/time & $V_{0}$ & $\$ 1500 /$ setup \\
$\mu$ & 0.0015 & $C_{H}^{M}$ & $\$ 0.05 /$ unit/unit time \\
$\theta_{0}$ & 0.00002 & $C_{F T}^{M}$ & $\$ 0.7 /$ unit shipment \\
$C_{V T}^{M}$ & $\$ 0.1 /$ container capacity & $C_{F C}^{M}$ & $\$ 0.2 /$ unit shipment \\
$C_{V C}^{M C}$ & $\$ 0.1 /$ container capacity & $\gamma$ & 0.6 unit \\
$C_{H}^{R}$ & $\$ 0.35 /$ unit & $\pi_{0}$ & $\$ 150 /$ unit \\
$\varrho_{0}$ & 0.52 & $\sigma$ & 9 \\
$S$ & $\$ 70 /$ unit & $a$ & 0.3 \\
$b$ & 0.2 & $\eta$ & 2250 \\
\hline
\end{tabular}

\subsection{Special Cases}

Case 1 (Constant reorder point). Taking the constant reorder point $k=10$, the expected total cost increases to $\$ 4012.62$, which is more than $212.14 \%$ of the proposed study.

Case 2 (No investment for OCR). Taking investment for ordering cost $A=0$, the total cost becomes $\$ 1286.3$ which is more than $0.06 \%$ of the proposed study.

Case 3 (No investment for quality improvement). If there is no investment for quality improvement of the product that is $\theta_{0}=\theta=0.00002$, then the expected total cost is $\$ 63,366,846.54$, which is more than $4,929,177.38 \%$ of the proposed study. Clearly, the cost is very high. Thus, investment for quality improvement is very much important.

Case 4 (No investment for SCR). No investment for SCR increases the total cost of the supply chain and it becomes $\$ 1352.24$ which is more than $5.19 \%$ of the proposed study.

Case 5 (With SSSD policy). For SSSD policy, the total production quantity will be sent in one lot and for that case the first lot size $q$ is equal to the total production lot, that is $q=113.79$ and $n=1$. Then, the total cost becomes $\$ 1475.16$, which is more than $14.75 \%$ of the proposed study. This proves that SSMUD policy is more cost-saver than SSSD policy.

Case 6 (With SSMD policy). If the lot sizes are equal that is $\varsigma=1$, then the number of shipment must be increased and the total cost is increased. The expected total cost becomes $\$ 2218.04$, which is more than $72.54 \%$ of the proposed study. Thus, it is clear that the SSMUD policy is more practical than the SSMD policy.

Case 7 (With constant demand). Taking the demand $D=30$ as constant that is $\rho=1$, the expected total cost increases up to $\$ 2549.2$, which is more than $98.30 \%$ of the proposed study.

\subsection{Sensitivity Analysis}

The sensitivity analysis is given in Table 4 . From Table 4 it is observed that

1. with the increasing value of ordering cost, HC of the retailer, SC, defective cost, FTCEC of the manufacturer, the expected total cost of the supply chain decreases and with the increasing value of the HC, VTCEC of the manufacturer, the total cost increases. 
2. The SC is most effective on the total cost of the supply chain. Thus, the management has to take care regarding the SC and the investment for SCR is under control.

3. The HC, fixed and variable transportation cost, and carbon emission cost of the manufacturer has less impact on the total cost.

4. The reduction of the $\mathrm{HC}$ of the retailer increases the total cost of the supply chain but the reduction of the $\mathrm{HC}$ of the manufacturer increases the total cost of the supply chain.

Table 4. Sensitivity analysis.

\begin{tabular}{cllcll}
\hline Parameters & Changes & Changes in JATC (\%) & Parameters & Changes & Changes in JATC (\%) \\
\hline$V_{0}$ & $-50 \%$ & +208.68 & $A_{0}$ & $-50 \%$ & +2.43 \\
& $-25 \%$ & +57.73 & & $-25 \%$ & +1.21 \\
& $+25 \%$ & -27.84 & & $+25 \%$ & -1.18 \\
& $+50 \%$ & -43.05 & & $+50 \%$ & -2.35 \\
\hline$C_{H}^{M}$ & $-50 \%$ & -0.08 & $C_{F T}^{M}$ & $-50 \%$ & +0.19 \\
& $-25 \%$ & -0.04 & & $-25 \%$ & +0.06 \\
& $+25 \%$ & +0.04 & & $+25 \%$ & -0.06 \\
& $+50 \%$ & +0.08 & $C_{F C}^{M}$ & $-50 \%$ & +0.04 \\
\hline$C_{V T}^{M}$ & $-50 \%$ & -0.60 & & $-25 \%$ & +0.02 \\
& $-25 \%$ & -0.30 & & $+25 \%$ & -0.02 \\
& $+25 \%$ & +0.30 & & $+50 \%$ & -0.04 \\
\hline$C_{V C}^{M}$ & $+50 \%$ & +0.60 & $C_{H}^{R}$ & $-50 \%$ & +0.41 \\
& $-50 \%$ & -0.60 & & $-25 \%$ & +0.21 \\
& $-25 \%$ & -0.30 & & $+25 \%$ & -0.21 \\
& $+25 \%$ & +0.30 & & $+50 \%$ & -0.41 \\
\hline \multirow{2}{*}{$S$} & $+50 \%$ & +0.60 & & & \\
& $-50 \%$ & +388.45 & & & \\
& $-25 \%$ & +96.73 & & & \\
& $+25 \%$ & -42.39 & & & \\
& $+50 \%$ & -63.96 & & & \\
\hline
\end{tabular}

\subsection{Managerial Insights}

This study gives an example of how the unreliability of the manufactures occurs shortages and how to solve that problem by considering a backorder price discount. Increasing the value of service for products increases the demand for the product as the constant demand is not a practical scenario for all cases.

In this study, the demand is dependent on the service which is also very practical in the real scenario. If a manufacturer does not provide good service, then the demand for the product produced by the manufacturer may decrease. Even, the demand of a product may not be the same for all times. There are some products like drugs of diabetic and cancer whose demand is increasing day by day and for those products, SSSD or SSMD policy are not appropriate. For these types of products, SSMUID policy is very much appropriate and realistic. The delivered items in multi-time with lot-increasing lot sizes are very practical that is explained by the special case.

Investments are needed for any concerned player of a supply chain for reducing the SC and OC, maintaining the quality of the product, and the service of the manufacturer.

Lead time is an important part of an SCM. Therefore, investing money for lead time crashing within the SCM works smoothly. 


\subsection{Real Life Example}

There are so many practical examples of this field in real life. Some of the practical examples of this study are given below.

- A person goes to a shop of a specified company for spare parts of the car. However, that spare part of that company is unavailable at that time. So, the customer orders that part and return back. Now due to unreliability of the manufacturer, the retailer cannot deliver the spare part to the customer within the due date. The customer now decides to buy the same spare part from a different company. However, the quality of the same spare part of the substitute company is not as good as the original one. As a result, the car is not giving the optimum performance. In this way, due to the unreliability of the manufacturer the original company losses a customer along with the reputation.

- A person goes to a medical shop for buying a medicine prescribed by the doctor and finds that it is unavailable at all shops. The customer places an order of that medicine in a shop. However, due to the unreliability of manufacturer, the person is unable to get that at the due date. Then under compulsion and by the influence of the medical shopkeeper, the customer buys another medicine of the same generic but that is not working properly. Thus, the customer losses the faith from that medicine company and the demand for the medicine decreases.

\section{Conclusions}

The unequal lot size really helped the transportation system to transfer products from the manufacturer to the retailer, which is quite logical than the existing equal lot size scenario. The model proved the best way to reduce the VTCEC. It was found that the expected total cost was globally minimized with respect to the safety stock, lead time, investment to reduced ordering cost and SC, and a continuous investment to reduced the probability of converting the production system from "in-control" to "out-of-control" stage. It was clear that the variable reorder point reduced the total cost of the supply chain than the fixed reorder point. Investment for SCR, OCR, and quality appeared very much important for the reduction of the total cost of the supply chain. SSMUID policy is more profitable than SSSD and SSMD policy within the SCM.

Usually, the demand depends on various factors like availability, selling price, quality, service of the manufacturer. In this study, demand was dependent upon only on the service. To reduce the lead time, the processing time can be reduced. For solving the shortage problem, the two-stage safety stock can be applied as the unreliability within the manufacturer, which generates a bad reputation among the customers. These issues can be discussed and solved in the extended study of this model. If the expected shortage quantity cannot be measured by the known probability, then solving the issue of the unreliability will be more complicated. The distribution-free approach can help to solve this issue. This model can be extended by considering the smart manufacturing system along with radio-frequency identifier device (RFID) concept for identifying unreliable manufacturer.

Author Contributions: Conceptualization, methodology, validation, visualization, B.S.; software, S.K.H. and S.K.G.; formal analysis, S.K.H.; data curation, S.K.H. and B.S.; writing-original draft preparation, S.K.H.; writing-review and editing, B.S., S.K.H., and S.K.G.; supervision, investigation, resources, S.K.G., and B.S. All authors have read and agreed to the published version of the manuscript.

Funding: This research received no external funding.

Conflicts of Interest: There is no conflict of interest for the publication of the paper. 


\section{Abbreviations}

The following abbreviations are used in this manuscript.

$\begin{array}{ll}\text { SCR } & \text { Setup cost reduction } \\ \text { OCR } & \text { Ordering cost reduction } \\ \text { QI } & \text { Quality improvement } \\ \text { SL } & \text { Service level improvement } \\ \text { SC } & \text { Setup cost } \\ \text { SCM } & \text { Supply chain management } \\ \text { USCM } & \text { Unreliable supply chain management } \\ \text { LTCC } & \text { Lead time crashing cost } \\ \text { SSSD } & \text { Single-setup-single-delivery } \\ \text { SSMD } & \text { Single-setup-multi-delivery } \\ \text { SSMUD } & \text { Single-setup-multi-unequal-delivery } \\ \text { SSMUID } & \text { Single-setup-multi-unequal-increasing-delivery } \\ \text { TCEC } & \text { Transportation and carbon emission cost } \\ \text { FTCEC } & \text { Fixed transportation and carbon emission cost } \\ \text { VTCEC } & \text { Variable transportation and carbon emission cost }\end{array}$

\section{Notation}

\section{Index}

$i \quad(i=1,2, \ldots, n)$ lead time (minimum duration) components

$j \quad(j=1,2, \ldots, n)$ lead time (normal duration) components

Decision variables

I production investment per batch (\$/batch)

$q \quad$ initial lot size (unit)

$\varsigma \quad$ increasing rate of shipment lot size (unit)

$\rho \quad$ service of the manufacturer (in percentage)

$n \quad$ number of shipments (integer variable)

$\theta \quad$ final out-of-control movement probability

$k \quad$ safety factor of the retailer

A retailer's investment for reducing ordering cost per ordered batch (\$/unit)

$L \quad$ replenishment lead time (week)

$\pi_{x} \quad$ price discount for backorder per unit offered by the retailer ( $\$ /$ unit)

\section{Parameters}

$Q \quad$ ordered quantity (units)

$\alpha \quad$ yield of the manufacturer (in percentage)

$\kappa_{1}, \kappa_{2}$ parameters related to SL

$D$ demand rate (unit)

$P \quad$ production rate (unit)

$V_{0} \quad$ fixed initial SC of manufacturer before any investment is made (\$/setup)

$\mu \quad$ shape parameter for the SC investment

$C_{H}^{M} \quad \mathrm{HC}$ for the manufacturer (\$/unit/unit time)

$\theta_{0} \quad$ out-of-control movement probability (initial)

$I_{\theta}(\theta) \quad$ investment for reduction of out-of-control probability (\$/cycle)

$C_{F T}^{M} \quad$ manufacturer's transportation cost (fixed) (\$/unit)

$C_{V T}^{M} \quad$ manufacturer's transportation cost (variable) (\$/container)

$C_{F C}^{M} \quad$ manufacturer's carbon emission cost (fixed) (\$/unit)

$C_{V C}^{M} \quad$ manufacturer's carbon emission cost (variable) (\$/container)

$\gamma \quad$ capacity of the container

$\eta \quad$ scale parameter of the investment for service

$A_{0} \quad$ retailer's initial ordering cost (\$/order)

$\kappa \quad$ shape parameter for the SC investment

$r \quad$ reorder point of the retailer 


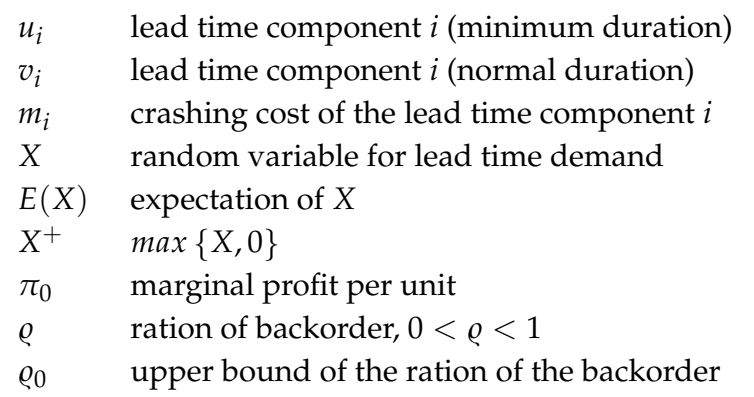

\section{Appendix A}

$$
\begin{gathered}
f(s)=\frac{s-1}{\varsigma^{n}-1}, g(\varsigma)=\frac{\varsigma^{n}+1}{\varsigma^{+1}}, \\
C(L)=m_{i}\left(L_{i-1}-L\right)+\sum_{j=1}^{i-1} m_{j}\left(v_{j}-u_{j}\right) \\
R_{1}\left(I, A, L, \pi_{x}, k\right)= \\
V_{0} e^{-\mu I}+I+n\left(C_{F T}^{S}+C_{F C}^{S}\right)+A_{0} e^{-\kappa A}+A+C(L)+\bar{\pi} \sigma \sqrt{L} \psi(k) \\
\bar{\pi}\left(\pi_{x}\right)=\pi_{0}-\varrho_{0} \pi_{x}+\frac{\varrho_{0}\left(\pi_{x}\right)^{2}}{\pi_{0}} \\
R_{2}(\theta)=\left(1-\frac{\kappa_{1} \rho^{\kappa_{2}}}{2 P}\right)+\frac{s \kappa_{1} \rho^{\kappa_{2}} \theta}{2}+\frac{1}{\gamma}\left(C_{V T}^{S}+C_{V C}^{S}\right) \\
R_{3}=\frac{1}{2}\left(C_{H}^{R}-C_{H}^{S}\right)
\end{gathered}
$$

\section{Appendix B}

For given value of $n$ and $L$ the hessian matrix $H$ is given below.

$$
H=\left[\begin{array}{cccccccc}
J_{I I} & J_{I \theta} & J_{I \zeta} & J_{I q} & J_{I A} & J_{I \pi_{x}} & J_{I k} & J_{I \rho} \\
J_{\theta I} & J_{\theta \theta} & J_{\theta \zeta} & J_{\theta q} & J_{\theta A} & J_{\theta \pi_{x}} & J_{\theta k} & J_{\theta \rho} \\
J_{\zeta I} & J_{\zeta \theta} & J_{\zeta \zeta} & J_{\zeta q} & J_{\zeta A} & J_{\zeta \pi_{x}} & J_{\zeta k} & J_{\zeta \rho} \\
J_{q I} & J_{q \theta} & J_{q \zeta} & J_{q q} & J_{q A} & J_{q \pi_{x}} & J_{q k} & J_{q \rho} \\
J_{A I} & J_{A \theta} & J_{A \zeta} & J_{A q} & J_{A A} & J_{A \pi_{x}} & J_{A k} & J_{A \rho} \\
J_{\pi_{x} I} & J_{\pi_{x} \theta} & J_{\pi_{x} \zeta} & J_{\pi_{x} q} & J_{\pi_{x} A} & J_{\pi_{x} \pi_{x}} & J_{\pi_{x} k} & J_{\pi_{x} \rho} \\
J_{k I} & J_{k \theta} & J_{k \zeta} & J_{k q} & J_{k A} & J_{k \pi_{x}} & J_{k k} & J_{k \rho} \\
J_{k I} & J_{k \theta} & J_{k \zeta} & J_{k q} & J_{k A} & J_{k \pi_{x}} & J_{k k} & J_{k \rho}
\end{array}\right]
$$

where $J=J A T C\left(I, \theta, \varsigma, n, q, A, L, \pi_{x}, k\right)$ and $J_{x y}=\frac{\partial^{2} J}{\partial x \partial y}$.

The second order partial derivatives at the optimal point $\left(I^{*}, \theta^{*}, \varsigma^{*}, q^{*}, A^{*}, L^{*}, \pi_{x}^{*}, k^{*}\right)$ are given below.

First column of Hessian matrix:

$$
J_{I I}=\frac{D^{*}}{q^{*}} f\left(\varsigma^{*}\right) \mu, J_{\theta I}=J_{\zeta I}=J_{q I}=J_{A I}=J_{\pi_{x} I}=J_{k I}=J_{\rho I}=0
$$

where $D^{*}=\kappa_{1}\left(\rho^{*}\right)^{\kappa_{2}}$.

Second column of Hessian matrix:

$J_{I \theta}=0, J_{\theta \theta}=\frac{a b}{\left(\theta^{*}\right)^{2}}, J_{\varsigma \theta}=-\frac{1}{2} q^{*} s D^{*} \frac{f^{\prime}\left(\varsigma^{*}\right)}{\left\{f(\varsigma\}^{2}\right.}, J_{q \theta}=\frac{s D^{*}}{2 f\left(\varsigma^{*}\right)}, J_{A \theta}=0, J_{\pi_{x} \theta}=0$, 
$J_{k \theta}=0, J_{\rho \theta}=\frac{1}{2} \frac{s q^{*}}{f(\varsigma)} \kappa_{1} \kappa_{2}\left(\rho^{*}\right)^{\kappa_{2}-1}$

Third column of Hessian matrix:

$J_{I \zeta}=0, J_{\theta \zeta}=-\frac{1}{2} q^{*} s D^{*} \frac{f^{\prime}\left(\varsigma^{*}\right)}{\left\{f\left(\varsigma^{*}\right)\right\}^{2}}, J_{\varsigma \zeta}=\left[g^{\prime \prime}\left(\varsigma^{*}\right)-\frac{f^{\prime \prime}\left(\varsigma^{*}\right) g^{\prime}\left(\varsigma^{*}\right)}{f^{\prime}\left(\varsigma^{*}\right)}\right] R_{3}^{*}-2 \frac{f^{\prime}\left(\varsigma^{*}\right) f^{\prime \prime}\left(\varsigma^{*}\right)}{\left\{f\left(\varsigma^{*}\right)\right\}^{3}} R_{2}^{*}$

$J_{q \zeta}=g^{\prime}\left(\varsigma^{*}\right) R_{3}^{*}-\left[\frac{D^{*}}{\left(q^{*}\right)^{2}} R_{1}^{*}+\frac{R_{2}^{*}}{\left\{f\left(\varsigma^{*}\right\}^{2}\right)}\right] f^{\prime}\left(\varsigma^{*}\right), J_{A \zeta}=0, J_{\pi_{x} \zeta}=\frac{D^{*}}{q^{*}} f^{\prime}\left(\varsigma^{*}\right)\left(\frac{2 \pi_{x}^{*}}{\pi_{0}}-1\right) \varrho_{0} \sigma \sqrt{L} \psi\left(k^{*}\right)$,

$J_{k \zeta}=\frac{D^{*}}{q} f^{\prime}\left(\varsigma^{*}\right) \bar{\pi} \sigma \sqrt{L}\left\{\Phi\left(k^{*}\right)-1\right\}, J_{\rho \varsigma}=\left[\frac{f^{\prime}\left(\varsigma^{*}\right)}{q^{*}} R_{1}^{*}-\frac{1}{2} \frac{q^{*}}{\left\{f\left(\varsigma^{*}\right\}^{2}\right)}\left(s \theta^{*}-\frac{1}{P}\right)\right] \kappa_{1} \kappa_{2}\left(\rho^{*}\right)^{\kappa_{2}-1}$

Fourth column of Hessian matrix:

$J_{I q}=0, J_{\theta q}=\frac{1}{2} \frac{s D^{*}}{f\left(\zeta^{*}\right)}, J_{\zeta q}=g^{\prime}\left(\varsigma^{*}\right) R_{3}^{*}-\left[\frac{D^{*}}{\left(q^{*}\right)^{2}} R_{1}^{*}+\frac{R_{2}^{*}}{\left\{f\left(\varsigma^{*}\right\}^{2}\right)}\right] f^{\prime}\left(\varsigma^{*}\right), J_{q q}=\frac{2 D *}{\left(q^{*}\right)^{3}} f\left(\varsigma^{*}\right) R_{1}^{*}$,

$J_{A q}=0, J_{\pi_{x} q}=-\frac{D^{*}}{\left(q^{*}\right)^{2}} f\left(\varsigma^{*}\right)\left(\frac{2 \pi_{x}^{*}}{\pi_{0}}-1\right) \varrho_{0} \sigma \sqrt{L} \psi\left(k^{*}\right), J_{k q}=-\frac{D^{*}}{\left(q^{*}\right)^{2}} f\left(\varsigma^{*}\right) \bar{\pi} \sigma \sqrt{L}\left\{\Phi\left(k^{*}\right)-1\right\}$,

$J_{\rho q}=\left[-\frac{f\left(\varsigma^{*}\right)}{\left(q^{*}\right)^{2}} R_{1}^{*}+\frac{1}{2} \frac{1}{f\left(\varsigma^{*}\right)}\left(s \theta^{*}-\frac{1}{P}\right)+\frac{1}{P}\right] \kappa_{1} \kappa_{2}\left(\rho^{*}\right)^{\kappa_{2}-1}$

Fifth column of Hessian matrix:

$J_{I A}=0, J_{\theta A}=0, J_{\varsigma A}=0, J_{q A}=0, J_{A A}=\frac{D^{*}}{q^{*}} f\left(\varsigma^{*}\right) \kappa, J_{\pi_{x} A}=0, J_{k A}=0, J_{\rho A}=0$

Sixth column of Hessian matrix:

$J_{I \pi_{x}}=0, J_{\theta \pi_{x}}=0, J_{\varsigma \pi_{x}}=\frac{D^{*}}{q^{*}} f^{\prime}\left(\varsigma^{*}\right)\left(\frac{2 \pi_{x}^{*}}{\pi_{0}}-1\right) \varrho_{0} \sigma \sqrt{L} \psi\left(k^{*}\right)$,

$J_{q \pi_{x}}=-\frac{D^{*}}{\left(q^{*}\right)^{2}} f\left(\varsigma^{*}\right)\left(\frac{2 \pi_{x}^{*}}{\pi_{0}}-1\right) \varrho_{0} \sigma \sqrt{L} \psi\left(k^{*}\right), J_{A \pi_{x}}=0, J_{\pi_{x} \pi_{x}}=2 \frac{D^{*}}{q^{*}} f\left(\varsigma^{*}\right) \frac{\varrho_{0}}{\pi_{0}} \sigma \sqrt{L} \psi\left(k^{*}\right)$,

$J_{k \pi_{x}}=\left[\frac{D^{*}}{q^{*}} f\left(\varsigma^{*}\right)\left(\frac{2 \pi_{x}^{*}}{\pi_{0}}-1\right)-\frac{C_{H}^{R}}{\pi_{0}}\right] \varrho_{0} \sigma \sqrt{L}\left\{\Phi\left(k^{*}\right)-1\right\}$,

$J_{\rho \pi_{x}}=\frac{f\left(\varsigma^{*}\right)}{q^{*}}\left(\frac{2 \pi_{x}^{*}}{\pi_{0}}-1\right) \varrho_{0} \sigma \sqrt{L} \psi\left(k^{*}\right) \kappa_{1} \kappa_{2}\left(\rho^{*}\right)^{\kappa_{2}-1}$

Seventh column of Hessian matrix:

$J_{I k}=0, J_{\theta k}=0, J_{\zeta k}=\frac{D^{*}}{q^{*}} f^{\prime}\left(\varsigma^{*}\right) \bar{\pi} \sigma \sqrt{L}\left\{\Phi\left(k^{*}\right)-1\right\}, J_{q k}=-\frac{D^{*}}{\left(q^{*}\right)^{2}} \bar{\pi} \sigma \sqrt{L}\left\{\Phi\left(k^{*}\right)-1\right\}$,

$J_{A k}=0, J_{\pi_{x} k}=\left[\frac{D^{*}}{q^{*}} f\left(\varsigma^{*}\right)\left(\frac{2 \pi_{x}^{*}}{\pi_{0}}-1\right)-\frac{C_{H}^{R}}{\pi_{0}}\right] \varrho_{0} \sigma \sqrt{L}\left\{\Phi\left(k^{*}\right)-1\right\}, J_{k k}=\frac{D^{*}}{q^{*}} f\left(\varsigma^{*}\right) \sigma \sqrt{L}$,

$J_{\rho k}=\frac{f\left(\varsigma^{*}\right)}{q^{*}} \bar{\pi} \sigma \sqrt{L}\left\{\Phi\left(k^{*}\right)-1\right\} \kappa_{1} \kappa_{2}\left(\rho^{*}\right)^{\kappa_{2}-1}$

Eighth column of Hessian matrix:

$J_{I \rho}=0, J_{\theta \rho}=\frac{1}{2} \frac{s q^{*}}{f\left(\varsigma^{*}\right)} \kappa_{1} \kappa_{2}\left(\rho^{*}\right)^{\kappa_{2}-1}, J_{\zeta \rho}=\left[\frac{f^{\prime}\left(\varsigma^{*}\right)}{q^{*}} R_{1}^{*}-\frac{1}{2} \frac{q^{*}}{\left\{f\left(\varsigma^{*}\right\}^{2}\right.}\left(s \theta^{*}-\frac{1}{P}\right)\right] \kappa_{1} \kappa_{2}\left(\rho^{*}\right)^{\kappa_{2}-1}$,

$J_{q \rho}=\left[-\frac{f\left(s^{*}\right)}{\left(q^{*}\right)^{2}} R_{1}^{*}+\frac{1}{2} \frac{1}{f\left(\varsigma^{*}\right)}\left(s \theta^{*}-\frac{1}{P}\right)+\frac{1}{P}\right] \kappa_{1} \kappa_{2}\left(\rho^{*}\right)^{\kappa_{2}-1}, J_{A \rho}=0$,

$\frac{\partial^{2} J}{\partial \pi_{x} \partial \rho}=\frac{f\left(\varsigma^{*}\right)}{q^{*}}\left(\frac{2 \pi_{x}^{*}}{\pi_{0}}-1\right) \varrho_{0} \sigma \sqrt{L} \psi\left(k^{*}\right) \kappa_{1} \kappa_{2}\left(\rho^{*}\right)^{\kappa_{2}-1}$,

$J_{k \rho}=\frac{f\left(\varsigma^{*}\right)}{q^{*}} \bar{\pi} \sigma \sqrt{L}\left\{\Phi\left(k^{*}\right)-1\right\} \kappa_{1} \kappa_{2}\left(\rho^{*}\right)^{\kappa_{2}-1}, J_{\rho \rho}=-2 \eta\left(\kappa_{2}-1\right) \rho^{*}$

First order minor: the value of the first order minor at the stationary point is

$$
\left|H_{11}\right|=\frac{D^{*}}{q^{*}} f\left(\varsigma^{*}\right) \mu>0
$$

Second order minor: the value of the second order minor at the stationary point is

$$
\left|H_{22}\right|=\frac{D^{*}}{q^{*}} f\left(\varsigma^{*}\right) \mu \frac{a b}{\left(\theta^{*}\right)^{2}}>0
$$


Third order minor: the value of the third order minor at the stationary point is

$$
\begin{aligned}
\left|H_{33}\right|= & \frac{D^{*}}{q^{*}} f\left(\varsigma^{*}\right) \mu\left[\frac{a b}{\left(\theta^{*}\right)^{2}}\left\{\left(g^{\prime \prime}\left(\varsigma^{*}\right)-\frac{f^{\prime \prime}\left(\varsigma^{*}\right) g^{\prime}\left(\varsigma^{*}\right)}{f^{\prime}\left(\varsigma^{*}\right)}\right) R_{3}^{*}-2 \frac{f^{\prime}\left(\varsigma^{*}\right) f^{\prime \prime}\left(\varsigma^{*}\right)}{\left\{f\left(\varsigma^{*}\right)\right\}^{3}} R_{2}^{*}\right\}-\right. \\
& \left.\frac{1}{4}\left\{q^{*} s D^{*} \frac{f^{\prime}\left(\varsigma^{*}\right)}{\left\{f\left(\varsigma^{*}\right)\right\}^{2}}\right\}^{2}\right]
\end{aligned}
$$

Clearly if $\frac{a b}{\left(\theta^{*}\right)^{2}}\left\{\left(g^{\prime \prime}\left(\varsigma^{*}\right)-\frac{f^{\prime \prime}\left(\varsigma^{*}\right) g^{\prime}\left(\varsigma^{*}\right)}{f^{\prime}\left(\varsigma^{*}\right)}\right) R_{3}^{*}-2 \frac{f^{\prime}\left(\varsigma^{*}\right) f^{\prime \prime}\left(\varsigma^{*}\right)}{\left\{f\left(\varsigma^{*}\right)\right\}^{3}} R_{2}^{*}\right\}>\frac{1}{4}\left\{q^{*} s D^{*} \frac{f^{\prime}\left(\varsigma^{*}\right)}{\left\{f\left(\varsigma^{*}\right)\right\}^{2}}\right\}^{2}$ then $\left|H_{33}\right|>0$

Fourth order minor: the value of the forth order minor at the stationary point is

$$
\begin{aligned}
\left|H_{44}\right|=\left|\begin{array}{llll}
J_{I I} & J_{I \theta} & J_{I \zeta} & J_{I q} \\
J_{\theta I} & J_{\theta \theta} & J_{\theta \zeta} & J_{\theta q} \\
J_{\zeta I} & J_{\zeta \theta} & J_{\zeta \zeta} & J_{\zeta q} \\
J_{q I} & J_{q \theta} & J_{q \zeta} & J_{q q}
\end{array}\right| & =\left|\begin{array}{cccc}
J_{I I} & 0 & 0 & 0 \\
0 & J_{\theta \theta} & J_{\theta \zeta} & J_{\theta q} \\
0 & J_{\zeta \theta} & J_{\zeta \zeta} & J_{\zeta q} \\
0 & J_{q \theta} & J_{q \zeta} & J_{q q}
\end{array}\right| \\
& =0+J_{\theta q}\left|\begin{array}{cccc}
J_{I I} & 0 & 0 \\
0 & J_{\zeta \theta} & J_{\zeta \zeta} \\
0 & J_{q \theta} & J_{q \zeta}
\end{array}\right|-J_{\zeta q}\left|\begin{array}{ccc}
J_{I I} & 0 & 0 \\
0 & J_{\theta \theta} & J_{\theta \zeta} \\
0 & J_{q \theta} & J_{q \zeta}
\end{array}\right|+J_{q q}\left|H_{33}\right|
\end{aligned}
$$

Since $J_{q q}\left|H_{33}\right|>0$ for

$$
\frac{a b}{\left(\theta^{*}\right)^{2}}\left\{\left(g^{\prime \prime}\left(\varsigma^{*}\right)-\frac{f^{\prime \prime}\left(\varsigma^{*}\right) g^{\prime}\left(\varsigma^{*}\right)}{f^{\prime}\left(\varsigma^{*}\right)}\right) R_{3}^{*}-2 \frac{f^{\prime}\left(\varsigma^{*}\right) f^{\prime \prime}\left(\varsigma^{*}\right)}{\left\{f\left(s^{*}\right)\right\}^{3}} R_{2}^{*}\right\}>\frac{1}{4}\left\{q^{*} s D^{*} \frac{f^{\prime}\left(\varsigma^{*}\right)}{\left\{f\left(\varsigma^{*}\right)\right\}^{2}}\right\}^{2}
$$

then $\left|H_{33}\right|>0$ therefore, $\left|H_{44}\right|>0$ if $J_{\theta q}\left|\begin{array}{ccc}J_{I I} & 0 & 0 \\ 0 & J_{\zeta \theta} & J_{\zeta \zeta} \\ 0 & J_{q \theta} & J_{q \zeta}\end{array}\right|-J_{\zeta q}\left|\begin{array}{ccc}J_{I I} & 0 & 0 \\ 0 & J_{\theta \theta} & J_{\theta \zeta} \\ 0 & J_{q \theta} & J_{q \zeta}\end{array}\right|>0$

i.e., if $\left|H_{44}\right|>0$ if $J_{\theta q}\left|\begin{array}{cc}J_{\zeta \theta} & J_{\zeta \zeta} \\ J_{q \theta} & J_{q \zeta}\end{array}\right|-J_{\zeta q}\left|\begin{array}{cc}J_{\theta \theta} & J_{\theta \zeta} \\ J_{q \theta} & J_{q \zeta}\end{array}\right|>0$, since $J_{I I}>0$

i.e., if $J_{\zeta \zeta}\left(J_{q \theta}\right)^{2}-2 J_{\zeta q} J_{\theta \zeta} J_{q \theta}+\left(J_{\varsigma q}\right)^{2} J_{\theta \theta}<0$

i.e., if $\left\{\left(J_{q \theta}\right)^{2}+\left(J_{\zeta q}\right)^{2}\right\}\left(J_{\zeta \zeta}-J_{q \theta}+J_{\theta \theta}\right)<0$, since $\left(J_{q \theta}\right)^{2} \leq\left(J_{q \theta}\right)^{2}+\left(J_{\zeta q}\right)^{2},\left(J_{\zeta q}\right)^{2} \leq\left(J_{q \theta}\right)^{2}+$ $\left(J_{\varsigma q}\right)^{2}$ and $-2 J_{q \theta} J_{\varsigma q} \leq\left(J_{q \theta}\right)^{2}+\left(J_{\varsigma q}\right)^{2}$

i.e., if $J_{\varsigma \zeta}-J_{q \theta}+J_{\theta \theta}<0$

i.e., if $J_{\theta \theta}<J_{q \theta}-J_{\zeta \zeta}$ and $J_{q \theta}>J_{\varsigma \zeta}$

i.e., if $\frac{a b}{\theta^{2}}<\frac{1}{2} \frac{s D^{*}}{f\left(\varsigma^{*}\right)}-\left(g^{\prime \prime}\left(\varsigma^{*}\right)-\frac{f^{\prime \prime}\left(\varsigma^{*}\right) g^{\prime}\left(\varsigma^{*}\right)}{f^{\prime}\left(\varsigma^{*}\right)}\right) R_{3}^{*}-2 \frac{f^{\prime}\left(\varsigma^{*}\right) f^{\prime \prime}\left(\varsigma^{*}\right)}{\left\{f\left(\varsigma^{*}\right)\right\}^{3}} R_{2}^{*}$ and $\frac{1}{2} \frac{s D^{*}}{f\left(\varsigma^{*}\right)}>\left(g^{\prime \prime}\left(\varsigma^{*}\right)-\right.$ $\left.\frac{f^{\prime \prime}\left(\varsigma^{*}\right) g^{\prime}\left(\varsigma^{*}\right)}{f^{\prime}\left(\varsigma^{*}\right)}\right) R_{3}^{*}-2 \frac{f^{\prime}\left(\varsigma^{*}\right) f^{\prime \prime}\left(\varsigma^{*}\right)}{\left\{f\left(\varsigma^{*}\right)\right\}^{3}} R_{2}^{*}$

Thus, $\left|H_{44}\right|>0$ if $\frac{a b}{\left(\theta^{*}\right)^{2}}\left\{\left(g^{\prime \prime}\left(\varsigma^{*}\right)-\frac{f^{\prime \prime}\left(s^{*}\right) g^{\prime}\left(\varsigma^{*}\right)}{f^{\prime}\left(\varsigma^{*}\right)}\right) R_{3}^{*}-2 \frac{f^{\prime}\left(\varsigma^{*}\right) f^{\prime \prime}\left(\varsigma^{*}\right)}{\left\{f\left(\varsigma^{*}\right)\right\}^{3}} R_{2}^{*}\right\}>\frac{1}{4}\left\{q^{*} s D^{*} \frac{f^{\prime}\left(\varsigma^{*}\right)}{\left\{f\left(s^{*}\right)\right\}^{2}}\right\}^{2}$, $\frac{a b}{\theta^{2}}<\frac{1}{2} \frac{s D^{*}}{f\left(\varsigma^{*}\right)}-\left(g^{\prime \prime}\left(\varsigma^{*}\right)-\frac{f^{\prime \prime}\left(s^{*}\right) g^{\prime}\left(s^{*}\right)}{f^{\prime}\left(s^{*}\right)}\right) R_{3}^{*}-2 \frac{f^{\prime}\left(\varsigma^{*}\right) f^{\prime \prime}\left(\varsigma^{*}\right)}{\left\{f\left(s^{*}\right)\right\}^{3}} R_{2}^{*}$ and $\frac{1}{2} \frac{s D^{*}}{f\left(s^{*}\right)}>\left(g^{\prime \prime}\left(\varsigma^{*}\right)-\frac{f^{\prime \prime}\left(s^{*}\right) g^{\prime}\left(s^{*}\right)}{f^{\prime}\left(s^{*}\right)}\right) R_{3}^{*}-$ $2 \frac{f^{\prime}\left(\varsigma^{*}\right) f^{\prime \prime}\left(\varsigma^{*}\right)}{\left\{f\left(\varsigma^{*}\right)\right\}^{3}} R_{2}^{*}$. 
Fifth order minor: the value of the fifth order minor at the stationary point is:

$$
\left|H_{55}\right|=\left|\begin{array}{ccccc}
J_{I I} & J_{I \theta} & J_{I \zeta} & J_{I q} & J_{I A} \\
J_{\theta I} & J_{\theta \theta} & J_{\theta \zeta} & J_{\theta q} & J_{\theta A} \\
J_{\zeta I} & J_{\zeta \theta} & J_{\zeta \zeta} & J_{\zeta q} & J_{\zeta A} \\
J_{q I} & J_{q \theta} & J_{q \zeta} & J_{q q} & J_{q A} \\
J_{A I} & J_{A \theta} & J_{A \zeta} & J_{A q} & J_{A A} \\
J_{\pi_{x} I} & J_{\pi_{x} \theta} & J_{\pi_{x} \zeta} & J_{\pi_{x} q} & J_{\pi_{x} A}
\end{array}\right|=\left|\begin{array}{ccccc}
J_{I I} & 0 & 0 & 0 & 0 \\
0 & J_{\theta \theta} & J_{\theta \zeta} & J_{\theta q} & 0 \\
0 & J_{\zeta \theta} & J_{\zeta \zeta} & J_{\zeta q} & 0 \\
0 & J_{q \theta} & J_{q \zeta} & J_{q q} & 0 \\
0 & 0 & 0 & 0 & J_{A A}
\end{array}\right|=J_{A A}\left|H_{44}\right|
$$

Since $J_{A A}>0,\left|H_{55}\right|>0$ if

$$
\begin{gathered}
\frac{a b}{\left(\theta^{*}\right)^{2}}\left\{\left(g^{\prime \prime}\left(\varsigma^{*}\right)-\frac{f^{\prime \prime}\left(\varsigma^{*}\right) g^{\prime}\left(\varsigma^{*}\right)}{f^{\prime}\left(\varsigma^{*}\right)}\right) R_{3}^{*}-2 \frac{f^{\prime}\left(\varsigma^{*}\right) f^{\prime \prime}\left(\varsigma^{*}\right)}{\left\{f\left(\varsigma^{*}\right)\right\}^{3}} R_{2}^{*}\right\}>\frac{1}{4}\left\{q^{*} s D^{*} \frac{f^{\prime}\left(\varsigma^{*}\right)}{\left\{f\left(\varsigma^{*}\right)\right\}^{2}}\right\}^{2}, \\
\frac{a b}{\theta^{2}}<\frac{1}{2} \frac{s D^{*}}{f\left(\varsigma^{*}\right)}-\left(g^{\prime \prime}\left(\varsigma^{*}\right)-\frac{f^{\prime \prime}\left(\varsigma^{*}\right) g^{\prime}\left(\varsigma^{*}\right)}{f^{\prime}\left(\varsigma^{*}\right)}\right) R_{3}^{*}-2 \frac{f^{\prime}\left(\varsigma^{*}\right) f^{\prime \prime}\left(\varsigma^{*}\right)}{\left\{f\left(\varsigma^{*}\right)\right\}^{3}} R_{2}^{*},
\end{gathered}
$$

and

$$
\frac{1}{2} \frac{s D^{*}}{f\left(\varsigma^{*}\right)}>\left(g^{\prime \prime}\left(\varsigma^{*}\right)-\frac{f^{\prime \prime}\left(\varsigma^{*}\right) g^{\prime}\left(\varsigma^{*}\right)}{f^{\prime}\left(\varsigma^{*}\right)}\right) R_{3}^{*}-2 \frac{f^{\prime}\left(\varsigma^{*}\right) f^{\prime \prime}\left(\varsigma^{*}\right)}{\left\{f\left(\varsigma^{*}\right)\right\}^{3}} R_{2}^{*}
$$

Sixth order minor:

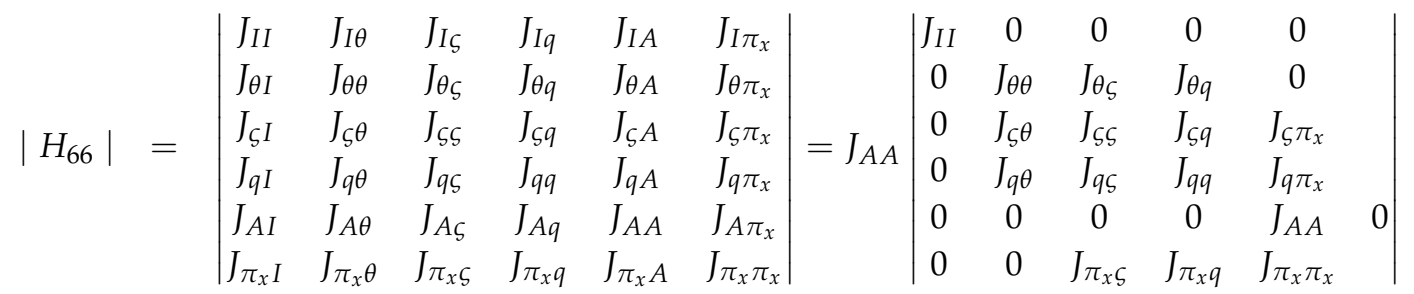

$$
\begin{aligned}
& =J_{A A} J_{\pi_{x} \zeta}\left|\begin{array}{cccc}
J_{I I} & 0 & 0 & 0 \\
0 & J_{\theta \theta} & J_{\theta q} & 0 \\
0 & J_{\zeta \theta} & J_{\zeta q} & J_{\zeta \pi_{x}} \\
0 & J_{q \theta} & J_{q q} & J_{q \pi_{x}}
\end{array}\right|-J_{A A} J_{\pi_{x} q}\left|\begin{array}{cccc}
J_{I I} & 0 & 0 & 0 \\
0 & J_{\theta \theta} & J_{\theta \zeta} & 0 \\
0 & J_{\zeta \theta} & J_{\zeta \zeta} & J_{\zeta \pi_{x}} \\
0 & J_{q \theta} & J_{q \zeta} & J_{q \pi_{x}}
\end{array}\right|+J_{A A} J_{\pi_{x} \pi_{x}}\left|H_{44}\right| \\
& =J_{A A} J_{\pi_{x} \zeta} J_{I I}\left|\begin{array}{ccc}
J_{\theta \theta} & J_{\theta q} & 0 \\
J_{\zeta \theta} & J_{\zeta q} & J_{\zeta \pi_{x}} \\
J_{q \theta} & J_{q q} & J_{q \pi_{x}}
\end{array}\right|-J_{A A} J_{\pi_{x} q} J_{I I}\left|\begin{array}{ccc}
J_{\theta \theta} & J_{\theta \zeta} & 0 \\
J_{\zeta \theta} & J_{\zeta \zeta} & J_{\zeta \pi_{x}} \\
J_{q \theta} & J_{q \zeta} & J_{q \pi_{x}}
\end{array}\right|+J_{A A} J_{\pi_{x} \pi_{x}}\left|H_{44}\right| \\
& =J_{A A} J_{I I}\left[J_{\pi_{x} \varsigma}\left\{J_{\theta \theta}\left(J_{\zeta q} J_{q \pi_{x}}-J_{\varsigma \pi_{x}} J_{q q}\right)-J_{\theta q}\left(J_{\zeta \theta} J_{q \pi_{x}}-J_{\varsigma \pi_{x}} J_{q \theta}\right)\right\}\right. \\
& \left.-J_{\pi_{x} q}\left\{J_{\theta \theta}\left(J_{\zeta \zeta} J_{q \pi_{x}}-J_{\zeta \pi_{x}} J_{q \zeta}\right)-J_{\theta \zeta}\left(J_{\zeta \theta} J_{q \pi_{x}}-J_{\varsigma \pi_{x}} J_{q \theta}\right)\right\}\right]+J_{A A} J_{\pi_{x} \pi_{x}}\left|H_{44}\right| \\
& =J_{A A} J_{I I}\left[2 J_{\pi_{x} \zeta} J_{\theta \theta} J_{\zeta q} J_{q \pi_{x}}-\left(J_{\pi_{x} \zeta}\right)^{2} J_{\theta \theta} J_{q q}-2 J_{\pi_{x} \zeta} J_{\theta q} J_{\zeta \theta} J_{q \pi_{x}}+\left(J_{\pi_{x} \zeta}\right)^{2}\left(J_{\theta q}\right)^{2}\right. \\
& \left.-\left(J_{\pi_{x} q}\right)^{2} J_{\theta \theta} J_{\zeta \zeta}+\left(J_{\pi_{x} q}\right)^{2}\left(J_{\theta \zeta}\right)^{2}\right]+J_{A A} J_{\pi_{x} \pi_{x}}\left|H_{44}\right|
\end{aligned}
$$

Since $J_{I I}>0, J_{A A}>0, J_{\pi_{x} \pi_{x}}>0,\left(J_{\pi_{x} \zeta}\right)^{2}\left(J_{\theta q}\right)^{2}+\left(J_{\pi_{x} q}\right)^{2}\left(J_{\theta \zeta}\right)^{2}>0$ and $\left|H_{44}\right|>0$ for $\frac{a b}{\left(\theta^{*}\right)^{2}}\left\{\left(g^{\prime \prime}\left(\varsigma^{*}\right)-\frac{f^{\prime \prime}\left(\varsigma^{*}\right) g^{\prime}\left(\varsigma^{*}\right)}{f^{\prime}\left(\varsigma^{*}\right)}\right) R_{3}^{*}-2 \frac{f^{\prime}\left(\varsigma^{*}\right) f^{\prime \prime}\left(\varsigma^{*}\right)}{\left\{f\left(\varsigma^{*}\right)\right\}^{3}} R_{2}^{*}\right\}>\frac{1}{4}\left\{q^{*} s D^{*} \frac{f^{\prime}\left(\varsigma^{*}\right)}{\left\{f\left(\varsigma^{*}\right)\right\}^{2}}\right\}^{2}, \frac{a b}{\theta^{2}}<\frac{1}{2} \frac{s D^{*}}{f\left(\varsigma^{*}\right)}-\left(g^{\prime \prime}\left(\varsigma^{*}\right)-\right.$ 
$\left.\frac{f^{\prime \prime}\left(\varsigma^{*}\right) g^{\prime}\left(\varsigma^{*}\right)}{f^{\prime}\left(\varsigma^{*}\right)}\right) R_{3}^{*}-2 \frac{f^{\prime}\left(\varsigma^{*}\right) f^{\prime \prime}\left(\varsigma^{*}\right)}{\left\{f\left(\varsigma^{*}\right)\right\}^{3}} R_{2}^{*}$ and $\frac{1}{2} \frac{s D^{*}}{f\left(\varsigma^{*}\right)}>\left(g^{\prime \prime}\left(\varsigma^{*}\right)-\frac{f^{\prime \prime}\left(\varsigma^{*}\right) g^{\prime}\left(\varsigma^{*}\right)}{f^{\prime}\left(\varsigma^{*}\right)}\right) R_{3}^{*}-2 \frac{f^{\prime}\left(\varsigma^{*}\right) f^{\prime \prime}\left(\varsigma^{*}\right)}{\left\{f\left(\varsigma^{*}\right)\right\}^{3}} R_{2}^{*}$ therefore, $\left|H_{66}\right|>0$ for $2 J_{\pi_{x} \zeta} J_{\theta \theta} J_{\zeta q} J_{q \pi_{x}}-\left(J_{\pi_{x} \zeta}\right)^{2} J_{\theta \theta} J_{q q}-2 J_{\pi_{x} \zeta} J_{\theta q} J_{\zeta \theta} J_{q \pi_{x}}-\left(J_{\pi_{x} q}\right)^{2} J_{\theta \theta} J_{\zeta \varsigma}>0$ i.e., if

$$
\begin{aligned}
& \left\{\frac{D}{q}\left(\frac{2 \pi_{x}}{\pi_{0}}-1\right) \varrho_{0} \sigma \sqrt{L} \psi(k)\right\}^{2}\left[-2 \frac{1}{q} \frac{a b}{\theta^{2}} f(\varsigma) f^{\prime}(\varsigma)\left\{g^{\prime}(\varsigma) R_{3}-\left(\frac{D}{q^{2}} R_{1}+\frac{R_{2}}{f^{2}(\varsigma)}\right) f^{\prime}(\varsigma)\right\}\right. \\
& -2 \frac{D}{q^{3}} \frac{a b}{\theta^{2}} f(\varsigma)\left\{f^{\prime}(\varsigma)\right\}^{2} R_{1}-\frac{1}{2}\left\{s D \frac{f^{\prime}(\varsigma)}{f(\varsigma)}\right\}^{2}-\frac{1}{q^{2}} \frac{a b}{\theta^{2}}\{f(\varsigma)\}^{2}\left\{\left(g^{\prime \prime}(\varsigma)-\frac{f^{\prime \prime}(\varsigma) g^{\prime}(\varsigma)}{f^{\prime}(\varsigma)}\right) R_{3}\right. \\
& \left.-2 \frac{f^{\prime}(\varsigma) f^{\prime \prime}(\varsigma)}{f^{3}(\varsigma)} R_{2}\right\}>0
\end{aligned}
$$

i.e., if

$$
\begin{aligned}
& {\left[2 \frac{1}{q} \frac{a b}{\theta^{2}} f(\varsigma) f^{\prime}(\varsigma)\left\{g^{\prime}(\varsigma) R_{3}-\left(\frac{D}{q^{2}} R_{1}+\frac{R_{2}}{f^{2}(\varsigma)}\right) f^{\prime}(\varsigma)\right\}+2 \frac{D}{q^{3}} \frac{a b}{\theta^{2}} f(\varsigma)\left\{f^{\prime}(\varsigma)\right\}^{2} R_{1}\right.} \\
& +\frac{1}{2}\left\{s D \frac{f^{\prime}(\varsigma)}{f(\varsigma)}\right\}^{2}+\frac{1}{q^{2}} \frac{a b}{\theta^{2}}\{f(\varsigma)\}^{2}\left\{\left(g^{\prime \prime}(\varsigma)-\frac{f^{\prime \prime}(\varsigma) g^{\prime}(\varsigma)}{f^{\prime}(\varsigma)}\right) R_{3}-2 \frac{f^{\prime}(\varsigma) f^{\prime \prime}(\varsigma)}{f^{3}(\varsigma)} R_{2}\right\}<0
\end{aligned}
$$

i.e., if

$$
\begin{aligned}
& 2 q f(\varsigma) f^{\prime}(\varsigma) g^{\prime}(\varsigma) R_{3}+\frac{q}{2} \frac{\theta}{a b}\left\{s D \frac{f^{\prime}(\varsigma)}{f(\varsigma)}\right\}^{2}+\{f(\varsigma)\}^{2} g^{\prime \prime}(\varsigma) R_{3}<2 q \frac{\left\{f^{\prime}(\varsigma)\right\}^{2}}{f(\varsigma)} R_{2} \\
& +\frac{\{f(\varsigma)\}^{2} f^{\prime \prime}(\varsigma) g^{\prime}(\varsigma)}{f^{\prime}(\varsigma)} R_{3}+2 \frac{f^{\prime}(\varsigma) f^{\prime \prime}(\varsigma)}{f(\varsigma)} R_{2}
\end{aligned}
$$

Thus, $\left|H_{66}\right|>0$ if

$$
\begin{gathered}
\frac{a b}{\left(\theta^{*}\right)^{2}}\left\{\left(g^{\prime \prime}\left(\varsigma^{*}\right)-\frac{f^{\prime \prime}\left(\varsigma^{*}\right) g^{\prime}\left(\varsigma^{*}\right)}{f^{\prime}\left(\varsigma^{*}\right)}\right) R_{3}^{*}-2 \frac{f^{\prime}\left(\varsigma^{*}\right) f^{\prime \prime}\left(\varsigma^{*}\right)}{\left\{f\left(\varsigma^{*}\right)\right\}^{3}} R_{2}^{*}\right\}>\frac{1}{4}\left\{q^{*} s D^{*} \frac{f^{\prime}\left(\varsigma^{*}\right)}{\left\{f\left(\varsigma^{*}\right)\right\}^{2}}\right\}^{2}, \\
\frac{a b}{\theta^{2}}<\frac{1}{2} \frac{s D^{*}}{f\left(\varsigma^{*}\right)}-\left(g^{\prime \prime}\left(\varsigma^{*}\right)-\frac{f^{\prime \prime}\left(\varsigma^{*}\right) g^{\prime}\left(\varsigma^{*}\right)}{f^{\prime}\left(\varsigma^{*}\right)}\right) R_{3}^{*}-2 \frac{f^{\prime}\left(\varsigma^{*}\right) f^{\prime \prime}\left(\varsigma^{*}\right)}{\left\{f\left(\varsigma^{*}\right)\right\}^{3}} R_{2}^{*} \\
\frac{1}{2} \frac{s D^{*}}{f\left(s^{*}\right)}>\left(g^{\prime \prime}\left(\varsigma^{*}\right)-\frac{f^{\prime \prime}\left(\varsigma^{*}\right) g^{\prime}\left(\varsigma^{*}\right)}{f^{\prime}\left(\varsigma^{*}\right)}\right) R_{3}^{*}-2 \frac{f^{\prime}\left(\varsigma^{*}\right) f^{\prime \prime}\left(\varsigma^{*}\right)}{\left\{f\left(\varsigma^{*}\right)\right\}^{3}} R_{2}^{*}
\end{gathered}
$$

and $2 q f(\varsigma) f^{\prime}(\varsigma) g^{\prime}(\varsigma) R_{3}+\frac{q}{2} \frac{\theta}{a b}\left\{s D \frac{f^{\prime}(\varsigma)}{f(\varsigma)}\right\}^{2}+\{f(\varsigma)\}^{2} g^{\prime \prime}(\varsigma) R_{3}<2 q \frac{\left\{f^{\prime}(\varsigma)\right\}^{2}}{f(\varsigma)} R_{2}+\frac{\{f(\varsigma)\}^{2} f^{\prime \prime}(\varsigma) g^{\prime}(\varsigma)}{f^{\prime}(\varsigma)} R_{3}+$ $2 \frac{f^{\prime}(\varsigma) f^{\prime \prime}(\varsigma)}{f(\varsigma)} R_{2}$

Seventh and eighth order minor: by the similar manner we can prove that the 7th and 8th order minors $\left|H_{77}\right|$ and $\left|H_{88}\right|$ are positive under some certain conditions.

\section{References}

1. Sarkar, M.; Lee, U.H. Optimum pricing strategy for complementary products with reservation price in a supply chain model. J. Indust. Manag. Opt. 2017, 13, 1553-1586. [CrossRef]

2. Ahmed, W.; Sarkar, B. Impact of carbon emissions in a sustainable supply chain management for a second generation biofuel. J. Clean. Prod. 2018, 186, 807-820. [CrossRef] 
3. Sarkar, B.; Saren, S.; Sinha, D.; Hur, S. Effect of unequal lot sizes, variable setup cost, and carbon emission cost in a supply chain model. Math. Prob. Eng. 2015, 2015, 469486. [CrossRef]

4. Goyel, S.K. An integrated inventory model for a single supplier-single customer problem. Int. J. Prod. Res. 1977, 15, 107-111. [CrossRef]

5. Banerjee, A. A joint economic-lot-size model for purchaser and vendor. Dec. Sci. 1986 17, 292-311. [CrossRef]

6. Hill, R.M. The single-vendor single-buyer integrated production-inventory model with a generalised policy Eur. J. Oper. Res. 1997, 97, 493-499. [CrossRef]

7. Goyal, S.K.; Nebebe, F. Determination of economic production-shipment policy for a single-vendor-singlebuyer system. Eur. J. Oper. Res. 2000, 121, 175-178, [CrossRef]

8. Sarkar, B.; Sana, S.; Chaudhuri, K.S. Optimal reliability, production lotsize and safety stock: An economic manufacturing quantity model. Int. J. Manag. Sci. Eng. Manag. 2010, 5, 192-202. [CrossRef]

9. Tiwari, S.; Ahmad, W.; Sarkar, B. Sustainable ordering policies for non-instantaneous deteriorating items under carbon emission and multi-trade-credit-policies. J. Clean. Prod. 2019, 240, 118183. [CrossRef]

10. Dey, B.K.; Pareek, S.; Tayyab, M.; Sarkar, B. Autonomation policy to control work-in-process inventory in a smart production system. Int. J. Prod. Res. 2020, doi:10.1080/00207543.2020.1722325. [CrossRef]

11. Tayyab, M.; Jemai, J.; Lim, H.; Sarkar, B. A sustainable development framework for a cleaner multi-item multi-stage textile production system with a process improvement initiative. J. Clean. Prod. 2020, 246, 119055. [CrossRef]

12. Saxena, N.; Sarkar, B.; Singh, S.R. Selection of remanufacturing/production cycles with an alternative market: A perspective on waste management. J. Clean. Prod. 2020, 245, 118935. [CrossRef]

13. Mishra, U.; Wu, J.Z.; Sarkar, B. A sustainable production-inventory model for a controllable carbon emissions rate under shortages. J. Clean. Prod. 2020, 256, 120268. [CrossRef]

14. Ullah, M.; Sarkar, B. Recovery-channel selection in a hybrid manufacturing-remanufacturing production model with RFID and product quality. Int. J. Prod. Econ. 2020, 219, 360-374. [CrossRef]

15. Mukhopadhyay, S.K.; Ma, H. Joint procurement and production decisions in remanufacturing under quality and demand uncertainty. Int. J. Prod. Econ. 2009, 120, 5-17. [CrossRef]

16. Fera, M.; Fruggiero, F.; Lambiase, A.; Macchiaroli, R.; Miranda, S. The role of uncertainty in supply chains under dynamic modeling. Int. J. Ind. Eng. Comp. 2017, 8, 119-140. [CrossRef]

17. Martino, G.; Fera, M.; Iannone, R.; Miranda, S. Supply chain risk assessment in the fashion retail industry: An analytic network process approach. Int. J. Appl. Eng. Res. 2017, 12, 140-154.

18. Inderfurth, K.; Kiesmüller, G.P. Exact and heuristic linear-inflation policies for an inventory model with random yield and arbitrary lead times. Eur. J. Oper. Res. 2015, 245, 109-210. [CrossRef]

19. Pagés-Bernaus, A.; Ramalhinho, H.; Juan, A.A.; Calvet, L. Designing e-commerce supply chains: A stochastic facility-location approach. Int. Trans. Oper. Res. 2019, 26, 507-528. [CrossRef]

20. Sawik, T. Disruption mitigation and recovery in supply chains using portfolio approach. Omega 2019, 84, 232-248. [CrossRef]

21. Xu, S.; Zhang, X.; Feng, L.; Yang, W. Disruption risks in supply chain management: A literature review based on bibliometric analysis. Int. J. Prod. Res. 2020, doi:10.1080/00207543.2020.1717011. [CrossRef]

22. Kaczmarczyk, W. Valid inequalities for proportional lot-sizing and scheduling problem with fictitious microperiods. Int. J. Prod. Econ. 2020, 219, 236-247. [CrossRef]

23. Chen, F.Y.; Krass, D. Inventory models with minimal service level constraints. Eur. J. Oper. Res. 2001, 134, 120-140. [CrossRef]

24. Hwang, H.S. Design of supply-chain logistics system considering service level. Comp. Indus. Eng. 2002, 43, 283-297. [CrossRef]

25. Chiu, S.W.; Ting, C.K.; Chiu, Y.S.P. Optimal production lot sizing with rework, scrap rate, and service level constraint. Math. Comp. Mod. 2007, 46, 535-549. [CrossRef]

26. Jodlbauer, H.; Reitner, S. Optimizing service-level and relevant cost for a stochastic multi-item cyclic production system. Int. J. Prod. Econ. 2018, 136, 306-317. [CrossRef]

27. Moon, I.; Shin, E.; Sarkar, B. Min-max distribution free continuous-review model with a service level constraint and variable lead time. Appl. Math. Comput. 2014, 229, 310-315. [CrossRef]

28. Shin, D.; Guchhait, R.; Sarkar, B.; Mittal, M. Controllable lead time, service level constraint, and transportation discounts in a continuous review inventory model. RAIRO-Oper. Res. 2016, 50, 921-934. [CrossRef] 
29. Albrecht, M. Optimization of safety stocks in models with an order service level objective or constraint. Eur. J. Oper. Res. 2017, 263, 900-909. [CrossRef]

30. Gruson, M.; Cordeau, J.F.; Jans, R. The impact of service level constraints in deterministic lot sizing with backlogging. Omega 2018, 79, 91-103. [CrossRef]

31. Jain, A.; Bala, R. Differentiated or integrated: Capacity and service level choice for differentiated products. Eur. J. Oper. Res. 2018, 266, 1025-1037. [CrossRef]

32. Lin, Y.J. Minimax distribution free procedure with backorder price discount. Int. J. Prod. Econ. 2008, 111, 118-128. [CrossRef]

33. Sarkar, B.; Guchhait, R.; Sarkar, M.; Pareek, S.; Kim, N. Impact of safety factors and setup time reduction in a two-echelon supply chain management. Rob. Comp. Int. Manuf. 2018, 55, 250-258. [CrossRef]

34. Porteus, E.L. Optimal lot sizing, process quality improvement and setup cost reduction. Oper. Res. 1986, 34, 137-144. [CrossRef]

35. Sarkar, B. A production-inventory model with probabilistic deterioration in two-echelon supply chain management. Appl. Math. Model. 2013, 37, 3138-3151. [CrossRef]

36. Sawik, B.; Faulin, J.; Pérez-Bernabeu, E. Multi-criteria optimization for fleet size with environmental aspects. Trans. Res. Proc. 2017, 27, 61-68. [CrossRef]

37. Glock, C.H. Lead time reduction strategies in a single-vendor-single-buyer integrated inventory model with lot size-dependent lead times and stochastic demand. Int. J. Prod. Econ. 2012, 136, 37-44. [CrossRef]

38. Sarkar, B.; Mandal, B.; Sarkar, S. Quality improvement and backorder price discount under controllable lead time in an inventory model. J. Manuf. Syst. 2015, 35, 26-36. [CrossRef]

39. Ouyang, L.Y.; Chen, C.K.; Chang, H.C., Quality improvement, setup cost and leadtime reductions in lot size reorder point models with an imperfect production process. Comp. Oper. Res. 2002, 29, 1701-1717. [CrossRef]

40. Lee, W.C. Inventory model involving controllable backorder rate and variable lead time demand with the mixtures of distribution. Appl. Math. Comput. 2005, 160, 701-717. [CrossRef]

41. Wu, J.W.; Lee, W.C.; Tasi, H.Y. Computational algorithmic procedure of optimal inventory policy involving a negative exponential crashing cost and variable lead time demand. Appl. Math. Comput. 2007, 140, 798-808. [CrossRef]

42. Sarkar, B.; Majumdar, A. Integrated vendor-buyer supply chain model with vendor's setup cost reduction. Appl. Math. Comput. 2013, 224, 362-371. [CrossRef]

43. Sarkar, B.; Ganguli, B.; Sarkar, M.; Pareek, S. Effect of variable transportation and carbon emission in a three-echelon supply chain model. Trans. Res. Part. E 2016, 91, 112-128. [CrossRef]

44. Majumder, A.; Jaggi, C.K.; Sarkar, B. A multi-retailer supply chain model with backorder and variable production cost. RAIRO-Oper. Res. 2018, 52, 943-954. [CrossRef]

45. Dey, B.K.; Sarkar, B.; Sarkar, M.; Pareek, M. An integrated inventory model involving discrete setup cost reduction, variable safety factors, selling price dependent demand, and investment. RAIRO-Oper. Res. 2019, 53, 39-57. [CrossRef]

46. Guchhait, R.; Pareek, S.; Sarkar, B. How does a radio frequency identification optimize the profit in an unreliable supply chain management? Mathematics 2019, 7, 490. [CrossRef]

47. Dey, B.K.; Sarkar, B.; Pareek, S. A two-echelon supply chain management with setup time and cost reduction, quality improvement and variable production rate. Mathematics 2019, 7, 328. [CrossRef]

48. Liao, C.J.; Shyu, C.H. An analytical determination of lead time with normal demand. Int. J. Oper. Prod. Manag. 1991, 11, 72-78. [CrossRef]

49. Pan, J.; Lo, M.C.; Hsiao, Y.C. Optimal reorder point inventory models withvariable lead time and backorder discount considerations. Eur. J. Oper. Res. 2004, 158, 488-505. [CrossRef]

50. Sarkar, B.; Ullah, M., Kim, N. Environmental and economic assessment of closed-loop supply chain with remanufacturing and returnable transport items. Comp. Indus. Eng. 2017, 111, 148-163. [CrossRef]

51. Moon, I.; Choi, S. A note on lead time and distributional assumptions in continuous review inventory models. Comput. Oper. Res. 1998, 25, 1007-1012. [CrossRef]

(C) 2020 by the authors. Licensee MDPI, Basel, Switzerland. This article is an open access article distributed under the terms and conditions of the Creative Commons Attribution (CC BY) license (http://creativecommons.org/licenses/by/4.0/). 